Yves Wittwer, Robert Eichler*, Ronald Zingg, Dominik Herrmann and Andreas Türler

\title{
The influence of gas purification and addition of macro amounts of metal-carbonyl complexes on the formation of single-atom metal-carbonyl- complexes
}

https://doi.org/10.1515/ract-2020-0036

Received April 8, 2020; accepted August 9, 2021;

published online September 2, 2021

Abstract: Using the Fast On-line Reaction Apparatus (FORA), the influence of various gas-purification columns onto the formation of metal carbonyl complexes (MCCs) under single-atom chemistry conditions was investigated. MCCs were synthesized from single atoms of Mo, Tc, Ru and $\mathrm{Rh}$ being produced by the spontaneous fission of ${ }^{252} \mathrm{Cf}$ and recoiling into a CO-gas containing carrier gas atmosphere. The in-situ synthesized MCCs were volatile enough to be transported by the carrier gas to a charcoal trap where they were adsorbed and their subsequent decay was registered by $\gamma$-spectrometry. It was found that the type and combination of purification columns used to clean the applied CO-gas strongly influences the obtained formation and transport yields for all MCCs. With the exception of Rh-carbonyl, intense gas-purification strategies resulted in reduced formation and transport yields for MCCs in comparison with less efficient or even completely missing purification setups. It was postulated that the observed reduction in yield might depend on the content of $\mathrm{Fe}(\mathrm{CO})_{5}$ and $\mathrm{Ni}(\mathrm{CO})_{4}$, as well as potentially other MCCs, in the CO-gas, being formed by the interaction between $\mathrm{CO}$ and the steel-surfaces of FORA as well as from impurities in the used charcoal traps. Subsequently, it was shown that macro amounts of $\mathrm{Fe}(\mathrm{CO})_{5}$, $\mathrm{Ni}(\mathrm{CO})_{4}, \mathrm{Mo}(\mathrm{CO})_{6}$ and $\mathrm{Re}_{2}(\mathrm{CO})_{10}$ added to the used process gas indeed increase significantly the overall yields for MCCs produced by ${ }^{252} \mathrm{Cf}$ fission products. $\mathrm{Ni}(\mathrm{CO})_{4}$ appeared the most potent to increase the yield. Therefore, it was used in more detailed investigations. Using isothermal chromatography, it was shown that $\mathrm{Ni}(\mathrm{CO})_{4}$ does not affect the

\footnotetext{
*Corresponding author: Robert Eichler, Paul Scherrer Institute, Villigen, Switzerland, E-mail: robert.eichler@psi.ch Yves Wittwer, Paul Scherrer Institute, Villigen, Switzerland; and University of Bern, Bern, Switzerland

Ronald Zingg and Andreas Türler, University of Bern, Bern, Switzerland

Dominik Herrmann, Paul Scherrer Institute, Villigen, Switzerland
}

speciation of carbonyl species produced by the ${ }^{252} \mathrm{Cf}$ fission product ${ }^{104} \mathrm{Mo}$. For ${ }^{107} \mathrm{Tc},{ }^{110} \mathrm{Ru}$ and ${ }^{111} \mathrm{Rh}$ a speciation change cannot be excluded. For ${ }^{111} \mathrm{Rh}$ a speciation change cannot be excluded. An inter-carbonyl transfer mechanism is suggested boosting the formation of MCCs. The current discovery might allow for new opportunities in various research fields, which are currently restricted by the low overall yields for MCCs produced under single-atom chemistry conditions. Examples are the chemical investigation of transactinides or the generation of radioactive ion beams from refractory metals at accelerators.

Keywords: carbonyl complexes; single atom chemistry; transition metals.

\section{Introduction}

The investigation of transactinides (TAs) is one of the most fundamental and challenging tasks modern chemistry has to offer. As TAs were not found to occur naturally until today, they have to be produced in nuclear fusion reactions being characterized by very low production rates ranging from a few atoms per minute up to atoms per month. Additionally, TAs generally have short half-lives in the range of seconds to minutes creating the need for very sensitive and fast chemical methods to investigate their properties [1-4].

Due to those limitations, experiments with TAs are often performed in the gas-phase. For TAs not being volatile in their elemental state, this requires a chemical transformation into volatile compounds. The harsh conditions behind heavy-ion beam irradiated targets only allowed the synthesis of thermally very stable compounds, namely oxides, halides and oxohalides in the past. The introduction of physical magnetic pre-separators between accelerator and chemical setup allowed to circumvent this limitation, giving access to the in-situ synthesis of more fragile compounds [5]. One class of those compounds are metal carbonyl complexes (MCCs), which all elements of groups 6 to 9 in the periodic table form. In theory, this 
allows investigating $\mathrm{Sg}$, Bh, Hs and Mt in the chemical state of their corresponding MCCs [3, 5].

Based on current knowledge from available literature, it is assumed that the volatile compounds formed from single atoms are indeed MCCs. For Mo and Ru, those are likely the corresponding electronically saturated species with 18 valence electrons, $\mathrm{Mo}(\mathrm{CO})_{6}$ and $\mathrm{Ru}(\mathrm{CO})_{5}$. Tc and $\mathrm{Rh}$ are known to form polynuclear MCCs. However, under single-atom chemistry conditions as applied here, the formation of polynuclear complexes can be excluded due to the large dilution of atoms. It is currently unknown what speciation the observed Tc and Rh compounds have formed [5-10]. The formation of 17 electron complexes or hydrogen containing complexes was suggested for group 7 elements [11], as well as for group 9 elements [12].

In 2014, the very first synthesis of a TA-MCC, $\mathrm{Sg}(\mathrm{CO})_{6}$ was achieved by an international group at RIKEN in Japan [6]. Despite the synthesis and product confirmation being successful, the study was suffering from low formation and transport yields for $\mathrm{Sg}(\mathrm{CO})_{6}$ (about 5-10\%) as well as for its homologues $\mathrm{Mo}(\mathrm{CO})_{6}\left(40 \%\right.$ yield) and $\mathrm{W}(\mathrm{CO})_{6}(10-20 \%$ yield) being studied using the same strategy. Currently, it appears that low overall yields are an intrinsic problem when working with MCCs under single-atom chemistry conditions [5].

A number of experimental studies were performed during the past years targeted at determining adsorption enthalpies of MCCs on quartz and PFA-TEFLON ${ }^{\circledR}$, their first bond dissociation energies (FBDEs) and the dependency of their overall yield on a limited number of reaction parameters, e.g., the CO-content of the applied process gas and the impact of $\mathrm{O}_{2}$ impurities [7-10,13-16]. To improve and expand the latter measurements, the Fast On-line Reaction Apparatus (FORA) was developed facilitating systematic investigations of the influence of a wide number of reaction parameters onto formation and transport of MCCs under single-atom chemistry conditions [17]. The goal is to provide deeper insight into the formation of MCCs in general and to suggest improved reaction conditions for the investigation of MCCs in the future. Aside from applications related to TAs, investigations concerning the chemistry of MCCs might provide benefits in other applications as well. MCCs are investigated as candidates for new pharmaceuticals [18-21], were found to be formed in nuclear waste [22] and are under investigation to provide access to new radioactive ion beams at accelerator facilities $[23,24]$.

The influence of process gas purification on the formation and transport of MCCs was investigated in this study using various purification columns. Derived from that, a new strategy for the synthesis of volatile compounds from Mo, Tc, Ru and $\mathrm{Rh}$ under single-atom chemistry conditions based on the addition of macro amounts of MCCs, namely $\mathrm{Fe}(\mathrm{CO})_{5}, \mathrm{Mo}(\mathrm{CO})_{6}, \mathrm{Re}_{2}(\mathrm{CO})_{10}$, and $\mathrm{Ni}(\mathrm{CO})_{4}$, is presented as a useful alternative to previous approaches.

At last, a tentative formation reaction mechanism including macro amounts of MCCs and an estimation of maximum overall yields, which can be expected using the new strategies, will be given.

\section{Experimental}

The FORA-system located at the University of Bern, Switzerland, was used for the investigations described here. It is described in detail elsewhere [17]. Briefly, the operation principle of FORA is based on a ${ }^{252} \mathrm{Cf}$-source, which is producing, amongst others, short-lived Mo, Tc, $\mathrm{Ru}$ and $\mathrm{Rh}$ isotopes over its spontaneous fission decay branch (about $3 \%$ ) at a rate of a few atoms per second. The fission products are recoiling from the source into a reaction chamber, which is constantly flushed by a CO-containing gas mixture. Depending on the reaction conditions, the elements Mo, Tc, Ru and Rh form volatile compounds in $\mathrm{CO}$, which are transported further by the gas stream. They are flushed through a 2 m-long PFA-TEFLON ${ }^{\circledR}$ capillary of $2 \mathrm{~mm}$ inner diameter to reach a charcoal trap where they are adsorbed long enough to decay. Their decay is monitored by a HPGe $y$-detector using the spectroscopic data summarized in Table 1. The obtained spectrometric signal is directly proportional to combined chemical and transport yields for the associated species under the applied reaction conditions. It is therefore possible to search for optimum reaction conditions for synthesis and transport of volatile Mo, Tc, Ru and Rh compounds under single-atom chemistry conditions and investigate the influence of various reaction parameters [17, 25].

Since FORA is operated as a closed gas loop, it can be continuously run without exchange of the process gas during the experiment. A series of different purification columns can be installed in the loop to maintain the purity of the used gas mixture. A Mass-Flow-Controller (MFC) is used to control the gas flow rate in the loop. Additionally, a pressure sensor and hygrometer are mounted in front of the reaction chamber. Additional gaseous substances, e.g. $\mathrm{H}_{2} \mathrm{O}, \mathrm{O}_{2}$ or inactive MCCs, can be easily added to the system and will distribute homogeneously in the process gas. It is not excluded that the charcoal trap used for catching the radioactive MCCs will partially also adsorb added impurities. However, in the closed system an equilibrium between impurities adsorbed to the charcoal and impurities remaining

Table 1: Isotopes investigated with their $\gamma$-lines and $\gamma$-branching ratios as described in [17].

\begin{tabular}{lrr}
\hline Nuclide & $\boldsymbol{\gamma}$-energy & $\gamma$-branching \\
\hline${ }^{104} \mathrm{Mo}$ & $68.8 / 69.7 \mathrm{keV}$ & $55 / 18 \%$ \\
${ }^{107} \mathrm{Tc}$ & $102.7 \mathrm{keV}$ & $21 \%$ \\
${ }^{110} \mathrm{Ru}$ & $112.2 \mathrm{keV}$ & $25 \%$ \\
${ }^{111} \mathrm{Rh}$ & $275.4 \mathrm{keV}$ & $71.9 \%$ \\
\hline
\end{tabular}

The two peaks investigated for ${ }^{104} \mathrm{Mo}$ were not properly resolved. They were integrated together. 
in the gas phase will be established. Therefore, addition of various compounds to test their influence on MCC formation is straightforward. Impurities will remain in the process gas either until they are removed by a dedicated purification column or until the process gas is exchanged.

The isotopes ${ }^{104} \mathrm{Mo},{ }^{107} \mathrm{Tc},{ }^{110} \mathrm{Ru}$ and ${ }^{111} \mathrm{Rh}$ were investigated as markers for their corresponding MCC compounds as described in [17]. Note that when using FORA, Mo, Tc, Ru and Rh are always simultaneously investigated during the same measurement.

Care must be taken to minimize the influence of precursor effects when choosing appropriate isotopes for investigation. The isotopes investigated here were chosen accordingly to avoid such effects. It was observed in previous studies $[17,25]$ that the four investigated elements show independent behavior. This would not be the case if their behaviors were significantly dominated by precursor effects. A detailed explanation on how these isotopes were selected to avoid precursor effects can be found in [17].

Figure 1 depicts schematically the FORA-setup as used during the investigations presented here. A more detailed schematic representation of the reaction chamber in the FORA setup is shown in Figure 2. Dew point, pressure and gas flow of the used process gas are continuously monitored and can therefore be assured to stay constant during operation. By default, two purification columns can be installed into the FORA-setup. Both columns can be bypassed completely or separately and can easily be replaced. Seven different columns were used during this study: A Sicapent ${ }^{\mathrm{TM}}$, MicroTorr $602 \mathrm{~F}$, MicroTorr $902 \mathrm{~F}$, nickel metal, $\mathrm{Mo}(\mathrm{CO})_{6}, \mathrm{Re}_{2}(\mathrm{CO})_{10}$ and heated charcoal. Sicapent ${ }^{\mathrm{TM}}$ was purchased from Merck, nickel (low carbon) from Johnson Matthey \& Brandenberger AG, $\mathrm{Mo}(\mathrm{CO})_{6}$ from Fluka and $\mathrm{Re}_{2}(\mathrm{CO})_{10}(98 \%)$ as well as the used charcoal were obtained from Sigma-Aldrich. Nickel was reduced prior to usage by exposing it to a flow $\left(25 \mathrm{~mL} / \mathrm{min}\right.$ ) of $100 \% \mathrm{H}_{2}$ (99.999\% from Carbagas) at $900{ }^{\circ} \mathrm{C}$ for $1 \mathrm{~h}$. The $\mathrm{Mo}(\mathrm{CO})_{6}$ and $\mathrm{Re}_{2}(\mathrm{CO})_{10}$ columns were heated to $100^{\circ} \mathrm{C}$ to facilitate the evaporation of the MCCs into the process gas online during operation. $300 \mathrm{mg}$ of nickel, $150 \mathrm{mg}$ of $\mathrm{Mo}(\mathrm{CO})_{6}$ and $\mathrm{Re}_{2}(\mathrm{CO})_{10}$ were placed between quartz plugs to keep the material in place inside of steel-pipes forming the corresponding columns. Empty steel-pipes treated similarly to the filled ones were shown in preparatory measurements to not impact the overall MCC-yield significantly. The results are included in the supporting information. The MicroTorr $602 \mathrm{~F}$ and MicroTorr $902 \mathrm{~F}$ cartridges are professional purification columns manufactured by SAES Pure Gas Products. The MicroTorr 602F cartridge is specifically designed to be operated with CO-gas. According to the manufacturer, it removes all impurities, except noble gases, $\mathrm{N}_{2}$ and $\mathrm{H}_{2}$, to concentrations of a few $\mathrm{ppb}$. It does not release any impurities into the process gas by itself [26, 27]. The MicroTorr $902 \mathrm{~F}$ column on the other hand is designed to be operated in noble gases and $\mathrm{N}_{2}$. As it contains metallic nickel, it will potentially release $\mathrm{Ni}(\mathrm{CO})_{4}$ upon contact with $\mathrm{CO}[27,28]$. The charcoal column was made by filling $800 \mathrm{mg}$ of charcoal into a steel-pipe with quartz-wool plugs at each side. An additional filter was placed right after the charcoal column (in gas flow direction), to prevent the accidental release of charcoal dust into the loop. The charcoal column was heated at $450-500{ }^{\circ} \mathrm{C}$ under vacuum overnight prior to application. Care was taken to avoid contact with air after the heating procedure. Note here the difference between the charcoal trap always used for detection behind the reaction chamber and the charcoal column used in only one study for gas purification in front of the reaction chamber.

The Sicapent ${ }^{\mathrm{TM}}$ is used to selectively remove moisture from the process gas, but no other impurities. The MicroTorr $602 \mathrm{~F}$ column is specifically designed to clear CO-gas. It removes various impurities

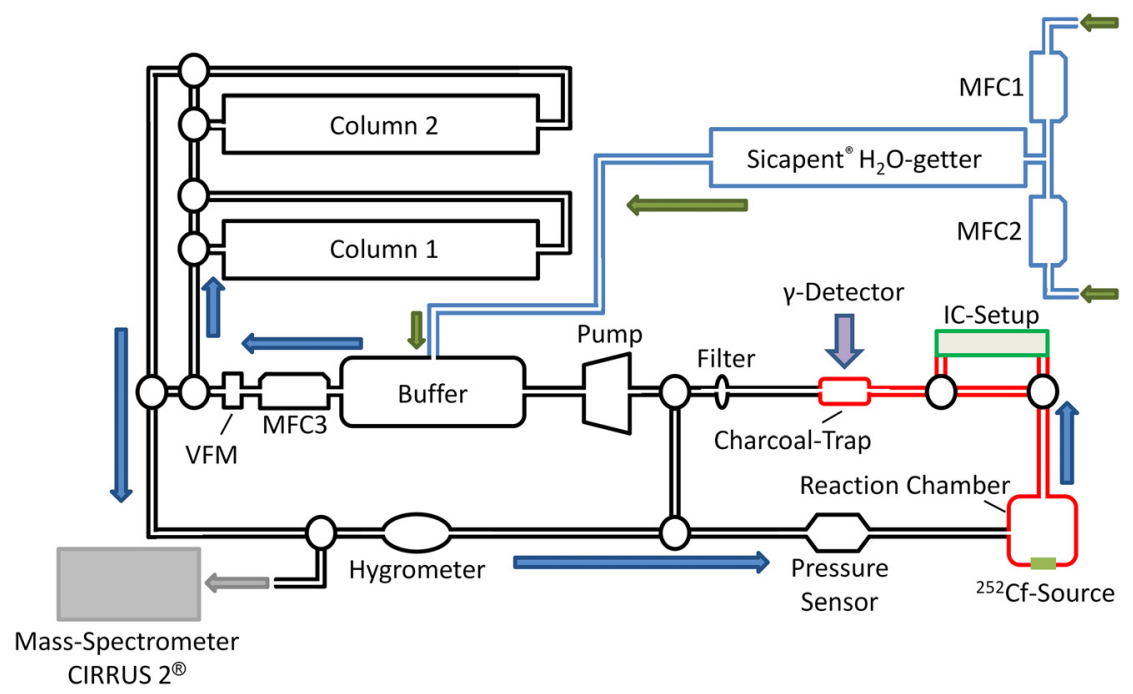

Figure 1: The FORA-system as used during the studies presented here. Three Mass-Flow-Controllers (MFCs) are installed, of which two (MFC1 and MFC2) are used to mix gases upon filling FORA while MFC3 is used to control the gas flow through the system. An analog Volume-FlowMeter (VFM) is used as an additional control of the internal gas flow. Pressure and dew point are monitored in front of the ${ }^{252} \mathrm{Cf}$-source. Up to two purification cartridges can be installed (Columns 1 and 2). They can be bypassed separately. The green arrows represent the gas flow pathway during initial filling of the system while the blue ones mark the flow during regular loop operation. The circles represent three-way valves. Parts shown in red are made from PFA-TEFLON ${ }^{\circledR}$, parts in black and blue are made from steel 316L. The parts in blue are only required for filling the system with fresh process gas. Additionally the isothermal chromatography (IC-Setup) is indicated, consisting of a quartz column that can be cooled down to low temperatures. This setup can be introduced into the loop to chromatographically separate volatile products. 


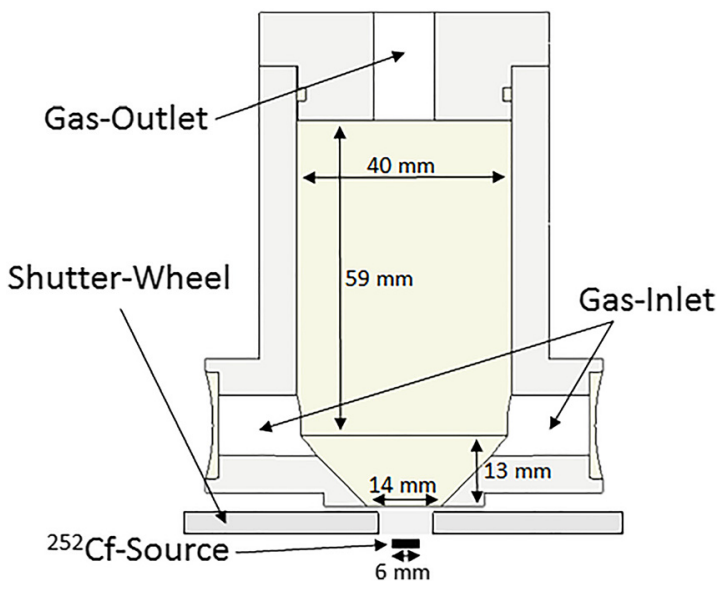

Figure 2: Schematic representation of the reaction chamber in the FORA setup [17]. The cross-section of the chamber is shown and the position of the ${ }^{252} \mathrm{Cf}$ source is indicated as a black bar. Process gas enters the reaction chamber through the two gas-inlets before leaving the chamber again through the gas outlet. Between reaction chamber and ${ }^{252} \mathrm{Cf}$ source, a shutter-wheel is mounted which can be used to open and close the reaction chamber towards the source [17].

including $\mathrm{O}_{2}, \mathrm{H}_{2} \mathrm{O}, \mathrm{CO}_{2}$, MCCs, acids, bases and various organics to impurity levels $<1 \mathrm{ppbV}$. The MicroTorr902F column removes the same impurities down to levels $<100 \mathrm{pptV}$. Additionally, it also removes $\mathrm{H}_{2}$. However, since the MicroTorr902F column is based on a medium containing nickel, it is not expected to work properly in a $\mathrm{CO}$ atmosphere. It emits $\mathrm{Ni}(\mathrm{CO})_{4}$ upon contact with $\mathrm{CO}$ [27].

$\mathrm{Fe}(\mathrm{CO})_{5}(>99.99 \%)$ was provided by Sigma-Aldrich. Since it is a liquid with high volatility at room temperature, it was injected into the running FORA-system using a dedicated setup depicted in Figure 3. This setup was designed to be easily attachable and removable from FORA. It was installed at the "Column 1" position (Figure 1). The procedure of injecting $\mathrm{Fe}(\mathrm{CO})_{5}$ was as follows: $\mathrm{V} 3$ was closed while the other valves were all opened. If necessary, a fresh membrane was attached in front of V1. The injection system was evacuated, before being filled with the investigated carrier gas. V2 was closed. Since $\mathrm{Fe}(\mathrm{CO})_{5}$ is toxic, the setup was detached between V2 and V3 before being transferred to a fume hood. There, $\mathrm{Fe}(\mathrm{CO})_{5}$ was injected with a syringe through the membrane into the volume between V1 and V2. V1 was closed directly afterwards to minimize intake of air through the pierced membrane. The setup was then re-attached to the FORA-loop and the space between V2 and V3 was evacuated using a turbo molecular pump Hi-Cube ${ }^{\circledR}$ from Pfeiffer Vacuum to remove in the connecting parts. To add $\mathrm{Fe}(\mathrm{CO})_{5}$, V4 was closed and V2/V3 were opened. The injection setup was thereby flushed with process gas from FORA and $\mathrm{Fe}(\mathrm{CO})_{5}$ was thus injected into the process gas flow.

A number of studies were devoted to further investigate the observed effects. $\mathrm{Ni}(\mathrm{CO})_{4}$ was chosen in all these investigations. Due to its in-situ synthesis, $\mathrm{Ni}(\mathrm{CO})_{4}$ is easier to be introduced in the FORA-system than the other investigated inactive MCCs without the risk of introducing air contaminants.

It is not trivial to convert the amounts of inactive MCCs added to the FORA-system into volume fractions. $\mathrm{Fe}(\mathrm{CO})_{5}$ is liquid at room temperature but has a high vapor pressure, so it can be assumed to completely evaporate upon being injected into the FORA-setup.

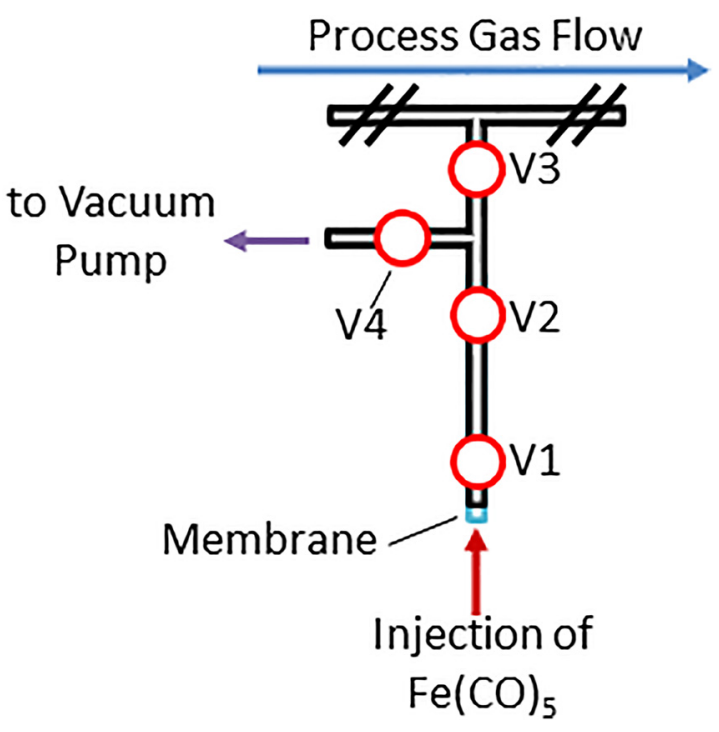

Figure 3: Setup used to add $\mathrm{Fe}(\mathrm{CO})_{5}$ into the FORA-system. The procedure is explained in the text. The blue part represents a membrane while the red circles represent two-way valves labeled V1 to V4. The system is based on Swagelok ${ }^{\circledR}$.

Assuming $\mathrm{Fe}(\mathrm{CO})_{5}$ to behave like an ideal gas, it can be calculated that adding $100 \mu \mathrm{L}$ of $\mathrm{Fe}(\mathrm{CO})_{5}$ into the FORA setup corresponds to roughly 0.2 Vol.- $\%$, which corresponds to the amounts used in this study. However, it must be emphasized that the real amount of $\mathrm{Fe}(\mathrm{CO})_{5}$ content in the process gas is lower by an unknown amount due to adsorption of $\mathrm{Fe}(\mathrm{CO})_{5}$ on the inner surfaces of FORA and especially on the used charcoal trap. For inactive $\mathrm{Mo}(\mathrm{CO})_{6}$ and $\mathrm{Rh}(\mathrm{CO})_{10}$, calculating the amount of inactive MCCs in the gas phase is much more difficult since both compounds are solids at room temperature. It can therefore not be assumed that they completely evaporate into the process gas of FORA and adsorption effects are expected to be more severe. Therefore, it is not possible to give exact volume fractions for those compounds when adding them to the FORA-setup. $\mathrm{Ni}(\mathrm{CO})_{4}$ on the other hand is synthesized in situ from metallic nickel. The volume fraction in FORA will therefore be again dependent on the adsorption on steel and especially charcoal as well as on the kinetics of the chemical formation reaction. Therefore, any volume fraction estimate would be arbitrary.

The yield dependence of fission-product MCCs in a system containing a nickel column upon insertion of a MicroTorr $602 \mathrm{~F}$ purification column was investigated. Using a different source of metallic nickel - a MicroTorr 902F column - the previous observations obtained using a nickel-filled steel-tube were confirmed. Additional mass spectrometric investigations proved the formation of $\mathrm{Ni}(\mathrm{CO})_{4}$ and its distribution along the entire process gas. For these studies a Cirrus $2^{\circledR}$ mass spectrometer from MKS instruments was used. The mass spectrometer was attached to the FORA system using three-way valves being installed before starting the corresponding measurement. Sampling was performed without interrupting the gas flow. The gas was injected directly into the ionization source of the mass spectrometer without any additional treatment.

To bolster speciation of single MCCs and to disprove the formation of mixed polynuclear MCCs isothermal chromatography (IC) measurements were performed using a coiled open quartz tube with a length of $2.4 \mathrm{~m}$ and inner diameter of $2 \mathrm{~mm}$. The tube was placed in a 
Dewar filled with ethanol. Dry ice and liquid $\mathrm{N}_{2}$ were used for cooling and keeping the temperature constant. A K-type thermocouple was used to monitor the temperature of the cooling bath. The IC setup was installed between the reaction chamber and charcoal trap. MCCs produced in the reaction chamber therefore had to travel through the cooled quartz column of the IC to be detected at the charcoal trap. The measurements were performed using $100 \% \mathrm{CO}$ at 1.00 bar and a gas flow rate of $1000 \mathrm{~mL} / \mathrm{min}$. A Sicapent $\mathrm{T}^{\mathrm{TM}}$ column was always online to prevent any ice formation in the IC column. From the results of the IC, the adsorption enthalpy of the produced, volatile Mo-compounds with and without addition of macro amounts of $\mathrm{Ni}(\mathrm{CO})_{4}$ could be compared with reference values. Thus, additional information towards a possible speciation of the reaction products under such conditions were obtained.

Lastly, measurements using a Sicapent ${ }^{\mathrm{TM}}$ column in combination with a MicroTorr $602 \mathrm{~F}$ cartridge for intense gas purification and measurements using the combination of a Sicapent ${ }^{\mathrm{TM}}$ and a nickel column were compared. In both cases $100 \%$ CO was used at a pressure of 1.5 bar and at a gas flow rate of $1800 \mathrm{~mL} / \mathrm{min}$. These conditions provided optimum reaction conditions according to our previous investigations [17, 25]. Note, $1800 \mathrm{~mL} / \mathrm{min}$ at 1.5 bar is the highest gas flow that can be reached with FORA in a reproducible way in this configuration.

Generally, in all experiments a lot of care was taken to avoid the accidental intake of air into the process gas at any time. The charcoal traps used for detection as well as the process gas were exchanged before each measurement series. The process gas was exchanged by evacuating the system using a turbo molecular pump Hi-Cube ${ }^{\circledR}$ (Pfeiffer Vacuum $\mathrm{GmbH}$ ), before filling it with fresh gas up to the desired pressure and gas flow. All charcoal traps were heated out prior to usage at $150{ }^{\circ} \mathrm{C}$ with a gas flow rate of $110 \mathrm{~mL} / \mathrm{min} \mathrm{N}_{2}$ applied. CO (99.995\%) and He (99.999\%) were obtained from Carbagas.

To allow for continuous measurements over long time spans, an automation script based on LabVIEW (V14.0.1) was used to automatically save and restart measurements. Spectra were recorded with a HPGe- $y$-detector and analyzed using Genie $2 \mathrm{k}^{\circledR}$. Both are products of Canberra $\mathrm{GmbH}$. For the analysis of small overlapping multi-peaks in the gamma spectra the multi peak fitting package of Origin ${ }^{\circledR}$ Pro was used. The data are generally corrected for the decay of ${ }^{252} \mathrm{Cf}$ for consistency.

\section{Results and discussion}

\subsection{Purification systems}

\subsubsection{Comparison of purification systems}

The synthesis of MCCs in FORA was investigated as a function of time over multiple days. In Figure 4, changes of yield are compared for three different purification setups installed in front of the FORA reaction chamber.

The data shown in Figure 4 were measured using 100\% $\mathrm{CO}$ at $1.00 \mathrm{bar}$ at a gas flow rate of $1000 \mathrm{~mL} / \mathrm{min}$. Consecutive $\gamma$-measurements were performed with a duration of $1 \mathrm{~h}$ each. All macroscopically observable parameters were held constant during the entire three measurement series.
The dew point did not exceed the detection limit of $-100^{\circ} \mathrm{C}$ for all measurements including a Sicapent ${ }^{\mathrm{TM}}$ column. During the measurements series using no columns at all, the dew point slowly increased from below -100 to $-83^{\circ} \mathrm{C}$ over time, corresponding to an increase of the water content in the carrier gas between about 20 and 400 ppbv.

An initial, time-dependent increase of overall yield is well visible for Mo, Tc and Ru. For Rh it is missing. Similar behaviors were already observed in the past using the FORA-setup [17]. Particularly, for Mo but to a smaller extent also for $\mathrm{Ru}$ and $\mathrm{Tc}$, the addition of a MicroTorr $602 \mathrm{~F}$ cartridge results in lower chemical and transport yields in comparison with measurements using only a Sicapent ${ }^{\mathrm{TM}}$ column or no purification columns at all. The remarkable exception is $\mathrm{Rh}$, which is the only investigated element for which the MicroTorr 602F purification column increased the obtained yield.

\subsubsection{Effect of intense gas purification}

After the observation that efficient cleaning of the carrier gas appears to lower the overall yield for MCCs, a long-term measurement series was performed to further investigate and confirm the previous observation. Figure 5 allows to estimate the effect of intense gas purification onto formation and transport yields of volatile Mo, Tc, Ru and Rh compounds. FORA was operated with $100 \%$ CO at 1.00 bar and applying a gas flow rate of $1000 \mathrm{~mL} / \mathrm{min}$. The dew point was below $-100{ }^{\circ} \mathrm{C}$ for the entire experiment. The process gas was not exchanged. Pressure and gas flow were constant. The only parameter varied was the type of gas purification. A Sicapent ${ }^{\mathrm{TM}}$ column was always used to avoid accumulation of $\mathrm{H}_{2} \mathrm{O}$. The MicroTorr 602F column could be introduced or bypassed using two three-way valves. It was not necessary to stop the gas flow for this. The MicroTorr $602 \mathrm{~F}$ column was filled with $100 \%$ CO prior to the experiment. Therefore, even the slightest pressure drop could be excluded upon insertion of the additional column.

During the first $64 \mathrm{~h}$, only a Sicapent ${ }^{\mathrm{TM}}$ column was used for gas purification. The usual increase of MCC-yield as a function of time is observed for all elements expect $R h$. After $65 \mathrm{~h}$, the MicroTorr 602F purification column was introduced. A continuous and strong decrease in yield is immediately observed for Mo and $\mathrm{Ru}$. The same behavior is observed for Tc but less pronounced. Rh is the only element showing an increase in yield upon addition of the additional column. After a total of $138 \mathrm{~h}$, the MicroTorr 602F column was removed again. For Mo and $\mathrm{Ru}$, this results in an increase in yield. For Tc the same is observed but to a weaker extend. For Rh, the yield decreases. 

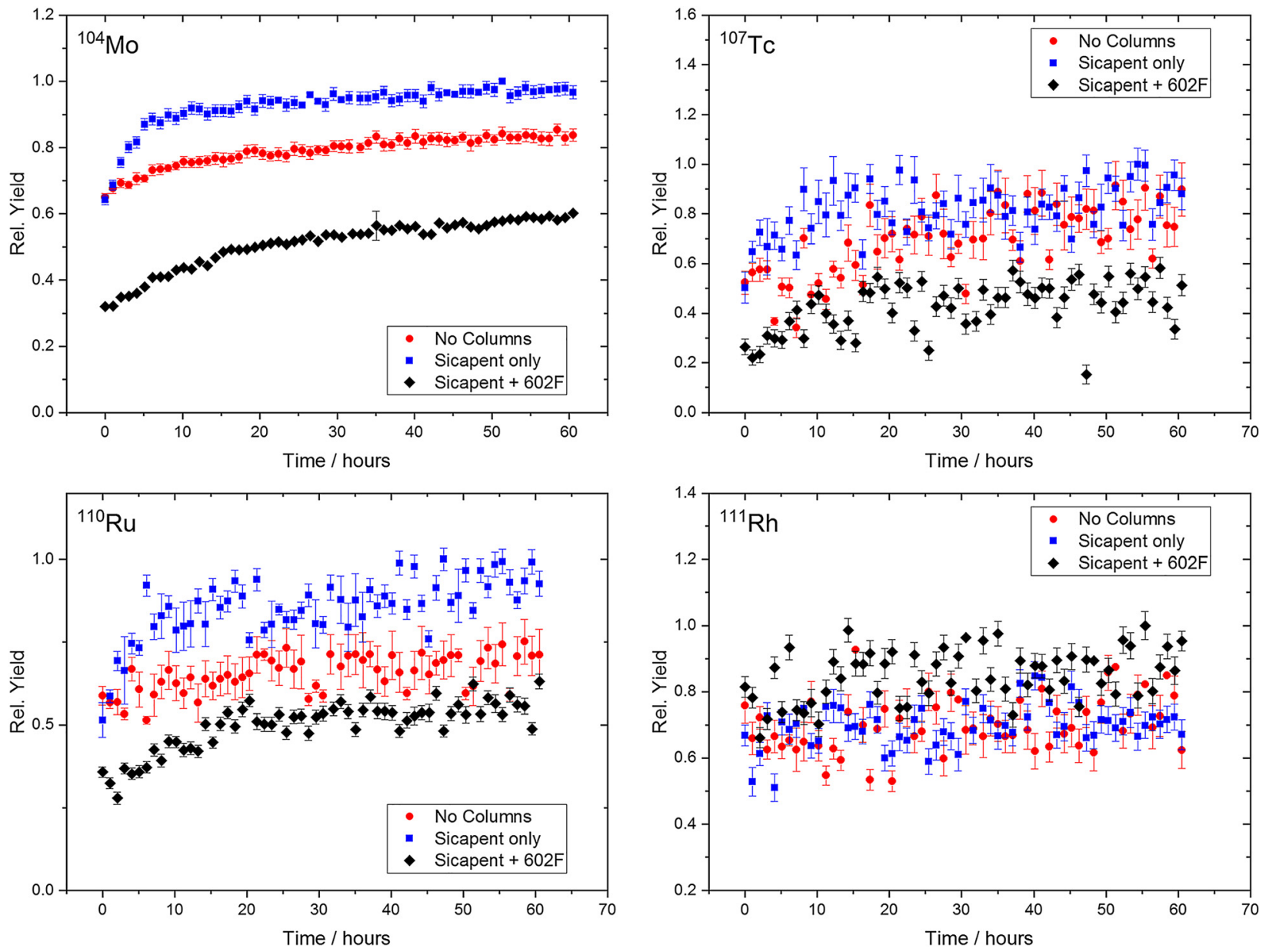

Figure 4: Results of long-term measurements comparing the change in MCC-yield over time for three different combinations of purification columns. Experimental details are given in the text below. The three compared purification setups are: No purification cartridges at all (red circles), only a Sicapent ${ }^{\mathrm{TM}}$ column (blue squares) and a Sicapent ${ }^{\mathrm{TM}}$ column followed by a MicroTorr $602 \mathrm{~F}$ cartridge (black diamonds). The data are shown for all four investigated isotopes and are normalized to the highest yield. The error bars correspond to the statistical error of the measurement.

An initial increase of formation and transport yield as a function of time is observed for MCCs of all elements expect $\mathrm{Rh}$ in Figures 4 and 5. This behavior was attributed in previous investigations partially to the desorption of $\mathrm{H}_{2} \mathrm{O}$ from the inner FORA-surfaces and its subsequent absorption by the used purification columns. It was shown in [17] that $\mathrm{H}_{2} \mathrm{O}$ reduces the formation and transport yields for MCCs of Mo and Ru even in small amounts. The effect of $\mathrm{H}_{2} \mathrm{O}$ onto Tc and $\mathrm{Rh}$ was found to be less pronounced, which is in agreement with the observations made here. The assumption that trace amounts of water lower MCC-yields, is also in agreement with the obtained maximum yields at varied purification condition. Yields obtained after about $12 \mathrm{~h}$ for a system without gas-purification are reduced in comparison to measurements during which a Sicapent ${ }^{\mathrm{TM}}$ column was used as a $\mathrm{H}_{2} \mathrm{O}$-getter (see Figure 4).
However, the moisture content of the process gas cannot explain the observation that a MicroTorr $602 \mathrm{~F}$ column reduces overall the MCC-yields. The yields obtained for using a MicroTorr $602 \mathrm{~F}$ professional purification column were generally the lowest. Since the MicroTorr $602 \mathrm{~F}$ column is also removing $\mathrm{H}_{2} \mathrm{O}$ from the process gas to $<1 \mathrm{ppb}$, the addition of this column into the loop would be expected to increase the yields. Additionally, the yields obtained without purification columns were found to be rather constant despite the increasing dew point, which is again not in agreement with the assumption that the effects are purely based on the reactions induced by $\mathrm{H}_{2} \mathrm{O}$ traces. Only large amounts (dew point $>-40^{\circ} \mathrm{C}$ ) of $\mathrm{H}_{2} \mathrm{O}$ were found in [17] to increase the overall yield for volatile Tc compounds while smaller amounts (dew-point $<-40{ }^{\circ} \mathrm{C}$ ), relevant for the current study, had no significant impact. Therefore, also the 

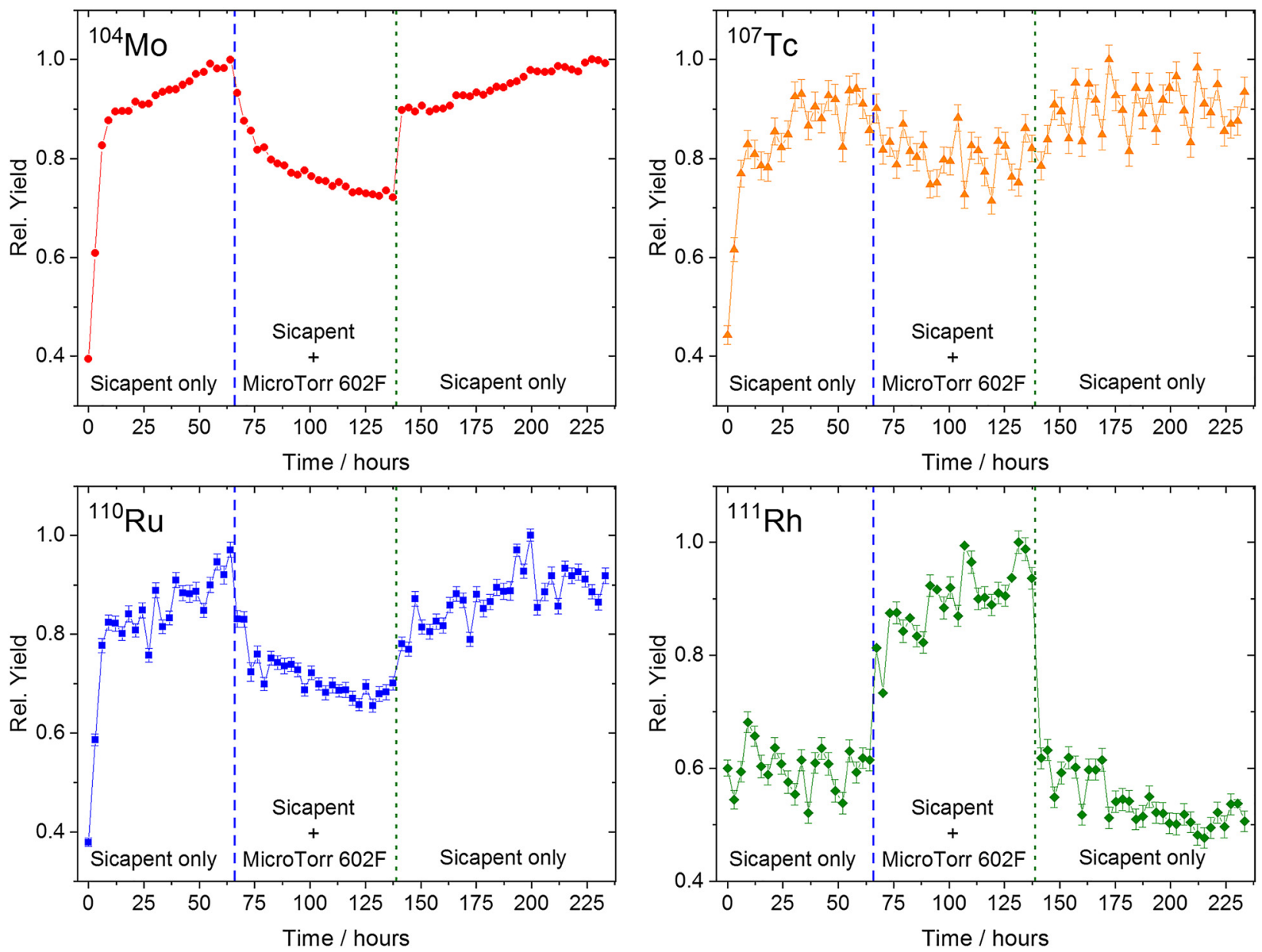

Figure 5: Results from long-term measurements investigating the effect of intense gas purification onto the formation of MCCs. Data are shown for all four investigated elements. The experimental conditions are given in the text. The active purification columns used in each step are written at the bottom of the plot. The vertical lines stand for changes to the purification system. Blue dashed line, insertion of the MicroTorr $602 \mathrm{~F}$ cartridge. Green dotted line, removal of the MicroTorr $602 \mathrm{~F}$-cartridge. The data are normalizes to the highest yield. The error bars correspond to the statistical error of the measurement. The connecting lines between the symbols shall guide the eye.

observations for Tc cannot be explained based on the moisture content of the process gas.

The observations related to the MicroTorr $602 \mathrm{~F}$ cartridge are fully confirmed by the data depicted in Figure 5. It appears that intense gas-purification is lowering the overall MCC-yields. The MicroTorr $602 \mathrm{~F}$ cartridge seems to remove a species boosting the synthesis and transport of MCCs. It is worth noting that despite the yield being reduced upon addition of the MicroTorr $602 \mathrm{~F}$ cartridge, it is still higher than the initial value obtained at the very beginning of the measurement series. It is therefore concluded that the observed behavior is actually a combination of two counteracting effects: The removal of $\mathrm{H}_{2} \mathrm{O}$ on one side and a possible yield decrease due to the removal of an unknown boosting impurity on the other side. After removal of the
MicroTorr 602F cartridge from the loop, a strong and fast increase of yields is observed for Mo, $\mathrm{Ru}$ followed to a smaller extend by Tc. This could be explained by assuming an in-situ synthesis of the favorable impurity inside of the FORA-setup accumulating in the carrier gas. $\mathrm{Rh}$ is the exception here. It actually behaves as a compound being very sensitive to various impurities. An improved purifi cation setup generally increases the yield for vola tile Rh-compounds. This is in agreement with previous investigations concerning the impact of impurities onto MCC formation, where Rh showed a high sensitivity towards small amounts of $\mathrm{O}_{2}$ which are removed by the MicroTorr 602F cartridge [17]. As derived in the next chapter, it is currently assumed that these yield increasing impurities are inactive MCCs, especially $\mathrm{Fe}(\mathrm{CO})_{5}$ and $\mathrm{Ni}(\mathrm{CO})_{4}$, which are 
formed in situ during operation of FORA with $\mathrm{CO}$ and which are removed from the process gas upon the introduction of purification columns.

\subsection{Carbonyl-boosters}

The observations presented in Figures 4 and 5 point towards the existence of an unidentified gas component which is able to increase chemical and/or transport yields for volatile species formed by Mo, Tc, Ru and potentially $\mathrm{Rh}$. The previously shown data suggest that such a component would be absorbed by the MicroTorr $602 \mathrm{~F}$ cartridge, but not by a Sicapent ${ }^{\mathrm{TM}}$ column. Additionally, it might be synthesized or/and accumulated over time inside of the FORA-setup giving rise to the continuously increasing yield within the first $12 \mathrm{~h}$ after each gas exchange as also observed in previous experiments [17, 25] and visible also in Figure 5 in the first $64 \mathrm{~h}$ and after the removal of the MicroTorr $602 \mathrm{~F}$ cartridge. The effect of multiple impurities onto formation and transport of MCCs was already investigated in $[17,25]$. Any influence from possible traces of $\mathrm{CO}_{2}, \mathrm{CH}_{4}, \mathrm{H}_{2}$, Ar and ambient air in the $\mathrm{CO}$-gas can therefore be safely excluded.

A common yet not investigated impurity typically present in CO-gas are inactive metal carbonyl-complexes, most importantly $\mathrm{Fe}(\mathrm{CO})_{5}$ and $\mathrm{Ni}(\mathrm{CO})_{4}$. The majority of the FORA-system is based on steel, 316L, which contains mostly iron, about $12.5-15 \%$ nickel, $17-19 \%$ chromium and 2.5-3\% molybdenum [29]. Those elements might form inactive MCCs upon contact with CO. Additionally, the charcoal used to trap the volatile reaction products formed by Mo, Tc, Ru and Rh contains metal impurities potentially forming inactive MCCs. The manufacturer gives the contents of Fe, Ni and Co in the used charcoal as $\leq 1 \%$ for $\mathrm{Fe}$ and $\leq 0.005 \%$ for $\mathrm{Ni}$ and Co. It is expected that such inactive MCCs are responsible for the effects described in chapter 3.1. The increase in yield as a function of time is expected to be related to removal of moisture on one side [17] and the in situ formation of inactive MCCs on the other. The decrease in yield upon introduction of efficient purification setups is expected to be caused by the removal of inactive MCCs from the process gas by the employed purification columns.

Particularly, the formation of $\mathrm{Fe}(\mathrm{CO})_{5}$, due to the vast abundance of iron in steel and charcoal, and of $\mathrm{Ni}(\mathrm{CO})_{4}$, due to its mild and rather efficient synthesis conditions, appear likely.

$$
\begin{aligned}
& \mathrm{Fe}+5 \mathrm{CO} \rightarrow \mathrm{Fe}(\mathrm{CO})_{5} \\
& \mathrm{Ni}+4 \mathrm{CO} \rightarrow \mathrm{Ni}(\mathrm{CO})_{4}
\end{aligned}
$$

Both compounds are volatile enough to be transported in the gas phase. Hence, a series of investigations concerning the addition of $\mathrm{Fe}(\mathrm{CO})_{5}, \mathrm{Ni}(\mathrm{CO})_{4}$ and other inactive MCCs was performed to evaluate their influence on the formation and transport yield of radioactive MCCs. Note the difference between inactive MCCs and radioactive MCCs to avoid confusion. Inactive MCC refers to macro amounts of MCCs, for example $\mathrm{Ni}(\mathrm{CO})_{4}$ and $\mathrm{Fe}(\mathrm{CO})_{5}$, which are added to the process gas. Radioactive MCC refers to MCCs formed by ${ }^{252} \mathrm{Cf}$ fission products in the FORA reaction chamber, namely ${ }^{104} \mathrm{Mo}(\mathrm{CO})_{6},{ }^{110} \mathrm{Ru}(\mathrm{CO})_{5}$ and the complexes formed by ${ }^{107} \mathrm{Tc}$ and ${ }^{111} \mathrm{Rh}$. To avoid confusion, substances that are expected to increase the yield for formation and transport of radioactive MCCs will be referred to as "boosters". Macro amounts of four different carbonyl complexes were tested for their potential use as boosters: $\mathrm{Fe}(\mathrm{CO})_{5}, \mathrm{Mo}(\mathrm{CO})_{6}, \mathrm{Re}_{2}(\mathrm{CO})_{10}$ and $\mathrm{Ni}(\mathrm{CO})_{4}$.

As it is visible in the measurements shown here, it was always waited for multiple hours before adding inactive MCCs to the process gas. During this time, continous measurements were already performed to observed time dependent changes in the FORA system and to make sure that the system reached a certain degree of stability before adding the inactive MCCs. It is important to point out that the goal of this initial waiting period was not to remove time-dependent effects, as this would require a lot of waiting time. Instead, the goal was to make sure that time dependent changes in yield are small in comparison to the actually targeted effects i.e., the effects of adding inactive MCCs to the system are much stronger than the effect the system shows as a function of time. If not pointed out otherwise in the corresponding discussion, the changes on yields caused by the introduction of boosters are always much stronger than the remaining time dependent yieldchanges after the initial waiting time.

\subsection{1 $\mathrm{Fe}(\mathrm{CO})_{5}$}

First experiments were performed using $\mathrm{Fe}(\mathrm{CO})_{5}$ as a booster. The procedure used to add $\mathrm{Fe}(\mathrm{CO})_{5}$ to the FORA process gas is described in the experimental part.

Figure 6 illustrates the effects of $\mathrm{Fe}(\mathrm{CO})_{5}$ onto the overall yield for radioactive MCCs. Before addition the usual increase of yield over time is visible. The addition of about $100 \mu \mathrm{L} \mathrm{Fe}(\mathrm{CO})_{5}$ increases the yield for volatile Mo, $\mathrm{Ru}$ and $\mathrm{Rh}$ species sharply. For ${ }^{104} \mathrm{Mo}$, the increase in signal is about $20 \%$, for ${ }^{110} \mathrm{Ru} 30 \%$ and for ${ }^{111} \mathrm{Rh} 60-70 \%$. Particularly, for Mo it is remarkable that the usual time dependent, slow increase of yield vanished after adding $\mathrm{Fe}(\mathrm{CO})_{5}$. For ${ }^{107} \mathrm{Tc}$, no significant effect was observed. In order to be sure that the observed effect was really caused by $\mathrm{Fe}(\mathrm{CO})_{5}$, an additional measurement without using CO-gas was performed. 

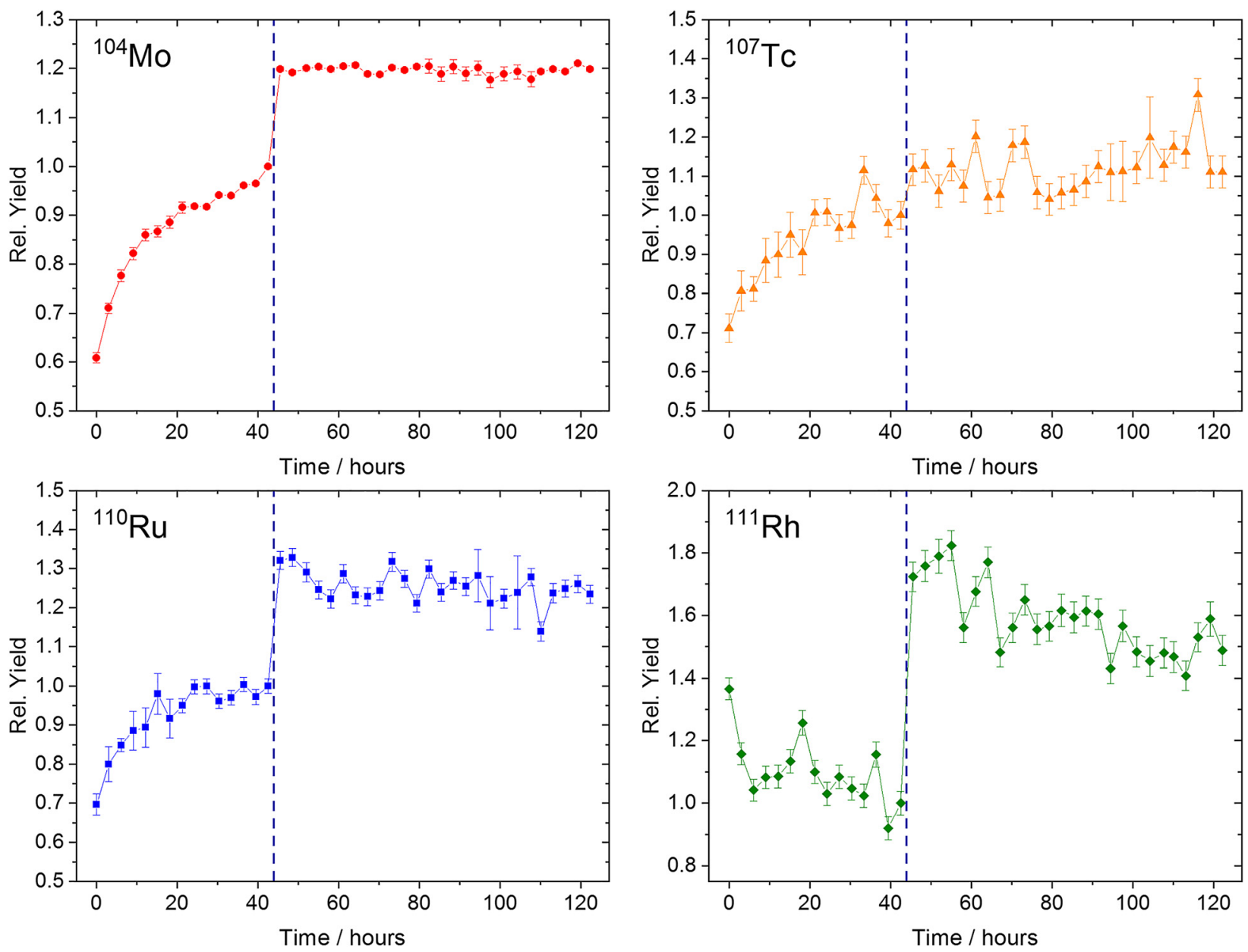

Figure 6: Effect of macroscopic Fe(CO) $)_{5}$ onto the yield of simultaneously measured radioactive $\mathrm{MCCs}$ in pure $\mathrm{CO}$. $\mathrm{Fe}(\mathrm{CO})_{5}$ was added to $100 \%$ $\mathrm{CO}$ at 1 bar and flowing at $1000 \mathrm{ml} / \mathrm{min}$ in the FORA-loop. Only a Sicapent ${ }^{\mathrm{TM}}$ column was used for purification. The data are normalized to the last yield measured before adding $\mathrm{Fe}(\mathrm{CO})_{5}$. The vertical, dashed, blue lines mark the point of $100 \mu \mathrm{Le}(\mathrm{CO})_{5}$ injection. The error bars represent the statistical error of the measurement.

Figure 7 shows the results from measurements performed in $100 \%$ He at 1 bar and a gas flow of $1000 \mathrm{ml} / \mathrm{min}$ in FORA. Initially, as expected, no volatile radioactive Mo, $\mathrm{Tc}, \mathrm{Ru}$ and $\mathrm{Rh}$ species were synthesized and transported while only He was flowing through the system. Using the same procedure as before, $100 \mu \mathrm{L}$ of $\mathrm{Fe}(\mathrm{CO})_{5}$ were injected $17 \mathrm{~h}$ after starting the continuous measurement series. The formation and transport of volatile $\mathrm{Mo}, \mathrm{Tc}, \mathrm{Ru}$ and $\mathrm{Rh}$ species is immediately observed. Adding another $100 \mu \mathrm{L}$ of $\mathrm{Fe}(\mathrm{CO})_{5}$ at the $21 \mathrm{~h}$ mark caused an additional increase in yield. Measurements were continued overnight without additional manipulation of the process gas. Over about $9 \mathrm{~h}$, a decrease in yield was observed until a decently stable signal was achieved. At the $42 \mathrm{~h}$ mark, a charcoal column (see experimental part) was introduced into the gas loop and heated to $300^{\circ} \mathrm{C}$, causing an immediate yield drop for $\mathrm{Mo}, \mathrm{Ru}$ and $\mathrm{Rh} .{ }^{107} \mathrm{Tc}$ is the exception. Its signal is reduced only slowly over time, even after insertion of the charcoal column.

The green, horizontal lines in Figure 7 mark the expected yield assuming complete decomposition of all added $\mathrm{Fe}(\mathrm{CO})_{5}$ into $\mathrm{Fe}$ and $\mathrm{CO}$ according to the reaction:

$$
\mathrm{Fe}(\mathrm{CO})_{5} \rightarrow \mathrm{Fe}+5 \mathrm{CO}
$$

or release of $\mathrm{CO}$ due to partial dimerization according to:

$$
2 \mathrm{Fe}(\mathrm{CO})_{5} \rightarrow \mathrm{Fe} 2(\mathrm{CO})_{9}+\mathrm{CO}
$$

The corresponding calculation is based on the assumption that the decomposition of the macroscopic $\mathrm{Fe}(\mathrm{CO})_{5}$ carbonyl will lead to a significant increase of the CO-concentration in the loop that otherwise contains only helium. The details are given in the supporting information. In all cases, the obtained yields upon addition of $\mathrm{Fe}(\mathrm{CO})_{5}$ are higher than the predicted ones. 

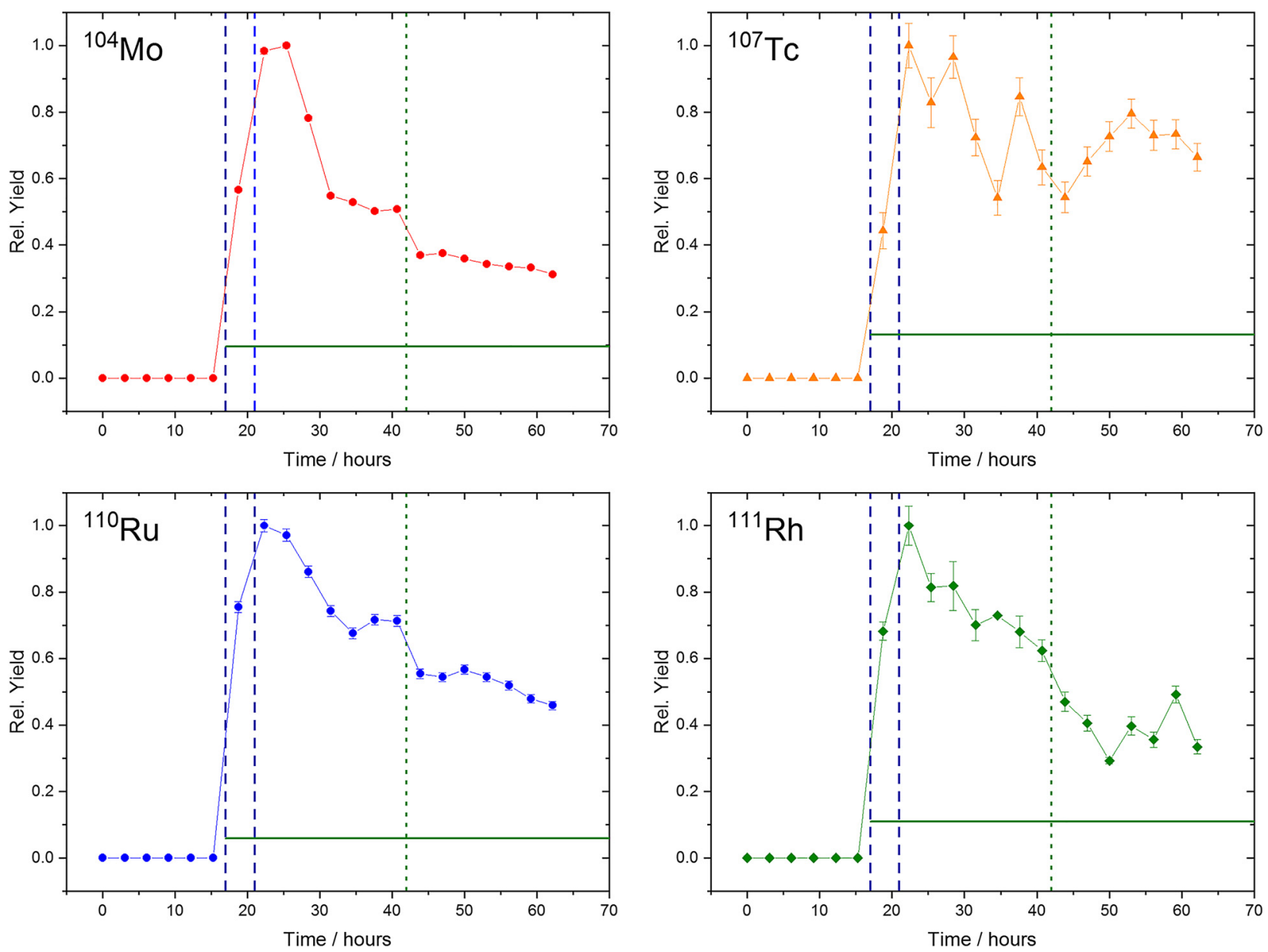

Figure 7: Effect of macroscopic Fe(CO) $)_{5}$ onto the yield of simultaneously measured radioactive $\mathrm{MCC}$ in pure $\mathrm{He}$. $\mathrm{Fe}(\mathrm{CO})_{5}$ was added in two steps to $100 \%$ He at a pressure of 1 bar and a gas flow of $1000 \mathrm{ml} / \mathrm{min}$ in FORA. Only a Sicapent ${ }^{\mathrm{TM}}$ column was used for purification. The dashed blue lines mark the time of the two $\mathrm{Fe}(\mathrm{CO})_{5}$ injections, $100 \mu \mathrm{L}$ each. The green, dotted lines mark the insertion of a charcoal column being heated to $300^{\circ} \mathrm{C}$. The data are normalize to the highest yield. The error bars represent the statistical error of the measurement. The horizontal, straight, green lines in each plot mark the expected yield upon assuming a complete decomposition of the added $\mathrm{Fe}(\mathrm{CO})_{5}$ into metallic Fe and $\mathrm{CO}$, thus increasing the $\mathrm{CO}$ content in the He gas loop (for details see text).

All inactive MCCs tested in this study showed different degrees of booster activity. All of them were able to increase selectively the yield for at least Mo and Ru carbonyl formation.

For $\mathrm{Fe}(\mathrm{CO})_{5}$ the obtained data show that it acts as a booster for volatile Mo, $\mathrm{Ru}$ and $\mathrm{Rh}$ species. As FORA is largely based on steel-tubes and the charcoal used as trap containing iron impurities, it is likely that $\mathrm{Fe}(\mathrm{CO})_{5}$ will accumulate in the process gas during prolonged loop operation. A slow increase of overall yields for volatile Mo, $\mathrm{Ru}$ and $\mathrm{Rh}$ species can be expected. Indeed, this increase is generally observed over time using the FORA-setup (see e.g., Figure 4). This observation can be on one hand related to the drying of the loop gas. On the other hand the slow accumulation of $\mathrm{Fe}(\mathrm{CO})_{5}$ and other inactive MCCs like
$\mathrm{Ni}(\mathrm{CO})_{4}$ and $\mathrm{Cr}(\mathrm{CO})_{6}$ can permanently increase the yield until a certain equilibrium saturation.

Experiments with $\mathrm{Fe}(\mathrm{CO})_{5}$ starting with pure He confirm the observations previously made in $\mathrm{CO}$. An increase in yield for Tc was observed in $\mathrm{He}$ as well upon $\mathrm{Fe}(\mathrm{CO})_{5}$ addition differently from the measurements in pure $\mathrm{CO} . \mathrm{Fe}(\mathrm{CO})_{5}$ is assumed to be not completely stable in He and therefore it might decompose or dimerize releasing free $\mathrm{CO}$ into the process gas. Assuming that the reaction with $\mathrm{Fe}(\mathrm{CO})$ to produce volatile species is more efficient than the reaction with pure $\mathrm{CO}$, the experimentally observed yield decreases until an equilibrium between free $\mathrm{CO}$ and $\mathrm{Fe}(\mathrm{CO})_{5}$ is reached. Hot charcoal provides a large surface onto which $\mathrm{Fe}(\mathrm{CO})_{5}$ will adsorb and decompose. Therefore, introducing a hot charcoal cartridge into the loop causes additional $\mathrm{Fe}(\mathrm{CO})_{5}$ to 
decompose into Fe and free $\mathrm{CO}$, which is clearly lowering the yield for the formation of volatile Mo, Ru and $\mathrm{Rh}$ species, despite an expected slight increase in $\mathrm{CO}$ concentration. This is not surprising if one assumes $\mathrm{Fe}(\mathrm{CO})_{5}$ to be a more efficient reagent for the formation of volatile $\mathrm{Mo}, \mathrm{Ru}$ and $\mathrm{Rh}$ species than pure $\mathrm{CO}$. Since the reaction with pure $\mathrm{CO}$ is disfavored in comparison to the reaction with $\mathrm{Fe}(\mathrm{CO})_{5}$, converting $\mathrm{Fe}(\mathrm{CO})_{5}$ into $\mathrm{Fe}$ and $\mathrm{CO}$ does not increase but lower the observed yield. The predicted overall yields assuming full decomposition of $\mathrm{Fe}(\mathrm{CO})_{5}$ upon insertion of hot charcoal were exceeded in all cases. It is possible that the hot charcoal did not completely decompose all $\mathrm{Fe}(\mathrm{CO})_{5}$ in the process gas. A direct reaction between thermalized atoms of $\mathrm{Mo}, \mathrm{Ru}$ and $\mathrm{Rh}$ and $\mathrm{Fe}(\mathrm{CO})_{5}$ can be tentatively concluded, which results in the synthesis of chemical species volatile enough to be transported and registered at the charcoal trap. Addition of more $\mathrm{Fe}(\mathrm{CO})_{5}$ enhances the formation of volatile species as expected.

The behavior observed for Tc is an exception in this regard. In pure $\mathrm{He}$, its yield does increase when $\mathrm{Fe}(\mathrm{CO})_{5}$ is added to the carrier gas but only decreases slowly, both, over time and after insertion of a heated charcoal column. It appears that Tc-MCC formation follows a different mechanism upon contact with $\mathrm{Fe}(\mathrm{CO})_{5}$ than the other elements investigated. As the reaction with $\mathrm{Fe}(\mathrm{CO})_{5}$ appears to be not largely favored over the reaction with free $\mathrm{CO}$, the decomposition of $\mathrm{Fe}(\mathrm{CO})_{5}$ does not lower the formation yield of Tc-MCCs. This is consistent with the observation in pure $\mathrm{CO}$, where the addition of $\mathrm{Fe}(\mathrm{CO})_{5}$ does not significantly increase the observed yield. The agreement with the data shown in Figure 5 is striking. If it is assumed that the observed decrease in yield upon intense gas purification is at least partially caused by the removal of inactive MCCs accumulating in the FORA-setup, one would indeed expect Tc to only slightly react upon insertion of the MicroTorr $602 \mathrm{~F}$ purification cartridge. Rh showed increasing yields upon insertion of the MicroTorr $602 \mathrm{~F}$ column despite its yield being enhanced by $\mathrm{Fe}(\mathrm{CO})_{5}$ as well. This is probably caused by its strong sensitivity towards small amounts of other impurities in the process gas, such as $\mathrm{O}_{2}$, which was previously shown particularly inhibitive towards Rh-MCC formation [17].

Note that the chemical and transport yields for volatile, radioactive species obtained with $\mathrm{Fe}(\mathrm{CO})_{5}$ in pure He are low in comparison with measurements performed in $\mathrm{CO}$, also due to stopping range issues [17]. Generally, the highest yields are observed in $\mathrm{CO}$ with $\mathrm{Fe}(\mathrm{CO})_{5}$ added, followed by pure CO. Nevertheless, the data imply that indeed $\mathrm{Fe}(\mathrm{CO})_{5}$ participates in the formation reaction of MCCs from single atomic fission products.
The other three investigated, inactive MCCs appear to behave as boosters as well. A direct quantitative comparison between the used, inactive MCCs is not trivial as they differ in volatility and thus different amounts are present in the gas phase.

\subsection{2 $\mathrm{Mo}(\mathrm{CO})_{6}$}

Inactive $\mathrm{Mo}(\mathrm{CO})_{6}$ added to $100 \% \mathrm{CO}$ was tested for its booster properties. It must not be confused with radioactive ${ }^{104} \mathrm{Mo}(\mathrm{CO})_{6}$, which is synthesized from ${ }^{252} \mathrm{Cf}$ fission products.

Like the previous inactive MCCs, inactive $\mathrm{Mo}(\mathrm{CO})_{6}$ was found to increase the yield for formation/transport of radioactive MCCs for Mo and $\mathrm{Ru}$ (see Figure 8). For Tc, no effect is visible as the increasing yield cannot be differentiated from the usual increase over time. The data for $\mathrm{Rh}$ are not showing a clear effect as well. For ${ }^{104} \mathrm{Mo}$ it is interesting to note that the increase in yield appears to be slower compared to the additions of $\mathrm{Fe}(\mathrm{CO})_{5}$ (see Section 3.2.1) and $\mathrm{Ni}(\mathrm{CO})_{4}$ (see Section 3.2.4).

\subsection{3 $\operatorname{Re}_{2}(\mathrm{CO})_{10}$}

$\operatorname{Re}_{2}(\mathrm{CO})_{10}$ addition was tested for its booster properties. It was assumed that $\operatorname{Re}_{2}(\mathrm{CO})_{10}$ might be especially well suited to increase the yield for Tc and Rh by the formation of mixed di-nuclear complexes (see Figure 9).

A strong boosting effect was observed for Mo and Rh, increasing the yield for Mo by about $40 \%$ and for Rh by about $60 \%$. For $\mathrm{Ru}$, the effect is only marginal while for Tc, no effect was observed at all.

\subsection{4 $\mathrm{Ni}(\mathrm{CO})_{4}$}

$\mathrm{Ni}(\mathrm{CO})_{4}$ is the only MCC that can be synthesized in large quantities at room temperature and ambient pressure by bringing metallic nickel into contact with $\mathrm{CO}$. It is a very toxic and air-sensitive compound. Therefore, it was synthesized in-situ by bringing CO into contact with freshly reduced nickel in a steel pipe (Ni-column) inside of the FORA-setup (see experimental part).

Like $\mathrm{Fe}(\mathrm{CO})_{5}$, a Ni-column inserted into the FORA-setup is increasing the yield for the formation and transport of volatile Mo, Tc, Ru and Rh compounds (see Figure 10). Differently from $\mathrm{Fe}(\mathrm{CO})_{5}$, all targeted elements are affected the same way. It must be emphasized that the observed increase in yield cannot be directly compared with the one observed for the addition of $\mathrm{Fe}(\mathrm{CO})_{5}$, since different amounts of $\mathrm{Fe}(\mathrm{CO})_{5} /$ nickel were added in the two 

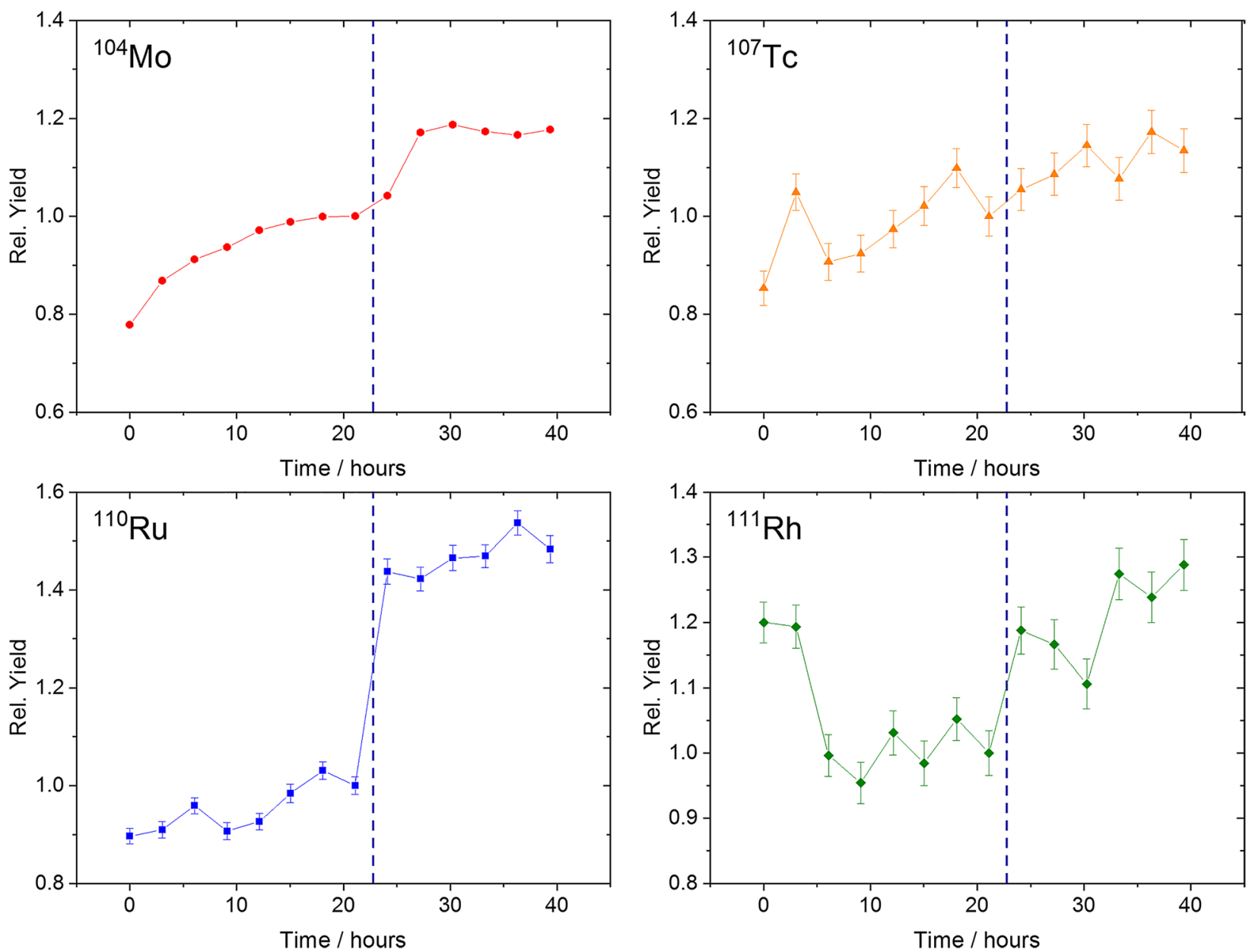

Figure 8: Effect of adding inactive $\mathrm{Mo}(\mathrm{CO})_{6}$ to the process gas. The time of inserting the $\mathrm{Mo}(\mathrm{CO})_{6}$ column held at $100^{\circ} \mathrm{C}$ into the FORA-loop is marked by the dashed blue lines. FORA was operated using $100 \% \mathrm{CO}$ at 1 bar at a gas flow of $1000 \mathrm{ml} / \mathrm{min}$. A Sicapent ${ }^{\mathrm{TM}}$ column was used for purification. The data are normalized to the last yield measured prior to the $\mathrm{Mo}(\mathrm{CO})_{6}$ addition. The error bars represent the statistical error of the measurement.

separated measurement series. Nevertheless, the gain in yield is remarkably high. For ${ }^{104} \mathrm{Mo}$ and ${ }^{110} \mathrm{Ru}$, the yield is doubled. For ${ }^{107} \mathrm{Tc}$ and ${ }^{111} \mathrm{Rh}$, it increased by almost $75 \%$.

\subsection{Detailed study of the $\mathrm{Ni}(\mathrm{CO})_{4}$ booster}

\subsubsection{Effect of gas purification onto carbonyl boosters}

$\mathrm{Ni}(\mathrm{CO})_{4}$ was found to be the only booster capable of increasing the absolute yields for all investigated radioactive MCCs. $\mathrm{Ni}(\mathrm{CO})_{4}$ has a low first carbonyl bond dissociation energy (FBDE) in comparison with other MCCs [30]. Assuming the booster effect of inactive MCCs to be based on ligand exchange reactions, the relative instability of the $\mathrm{Ni}$ $\mathrm{CO}$ bond might facilitate the $\mathrm{CO}$ exchange between $\mathrm{Ni}(\mathrm{CO})_{4}$ and Mo, Tc, Ru and Rh fission products. Additionally, fresh metallic nickel produced in the decomposition of $\mathrm{Ni}(\mathrm{CO})_{4}$, is known to be an efficient $\mathrm{O}_{2}$-getter, which is expected to additionally enhance its booster effect particularly for Rh.

As observed in Figure 11, the exchange of a MicroTorr $602 \mathrm{~F}$ cartridge with a freshly reduced Ni-column causes a fast and strong increase in yield for volatile compounds of $\mathrm{Mo}$, Tc and Ru. The high yield is stable until the Ni-column is again replaced with a MicroTorr $602 \mathrm{~F}$ for intense process gas purification (also for inactive MMCs), upon which the observed yield was found to decrease again over time. For $\mathrm{Rh}$, the opposite behavior was observed. If the yield enhancing effect observed for Mo, Tc and Ru upon addition of a Ni-column was only based on the gettering capabilities of metallic nickel, one would expect the yield for volatile $\mathrm{Rh}$ compounds to increase as well, as it was demonstrated 

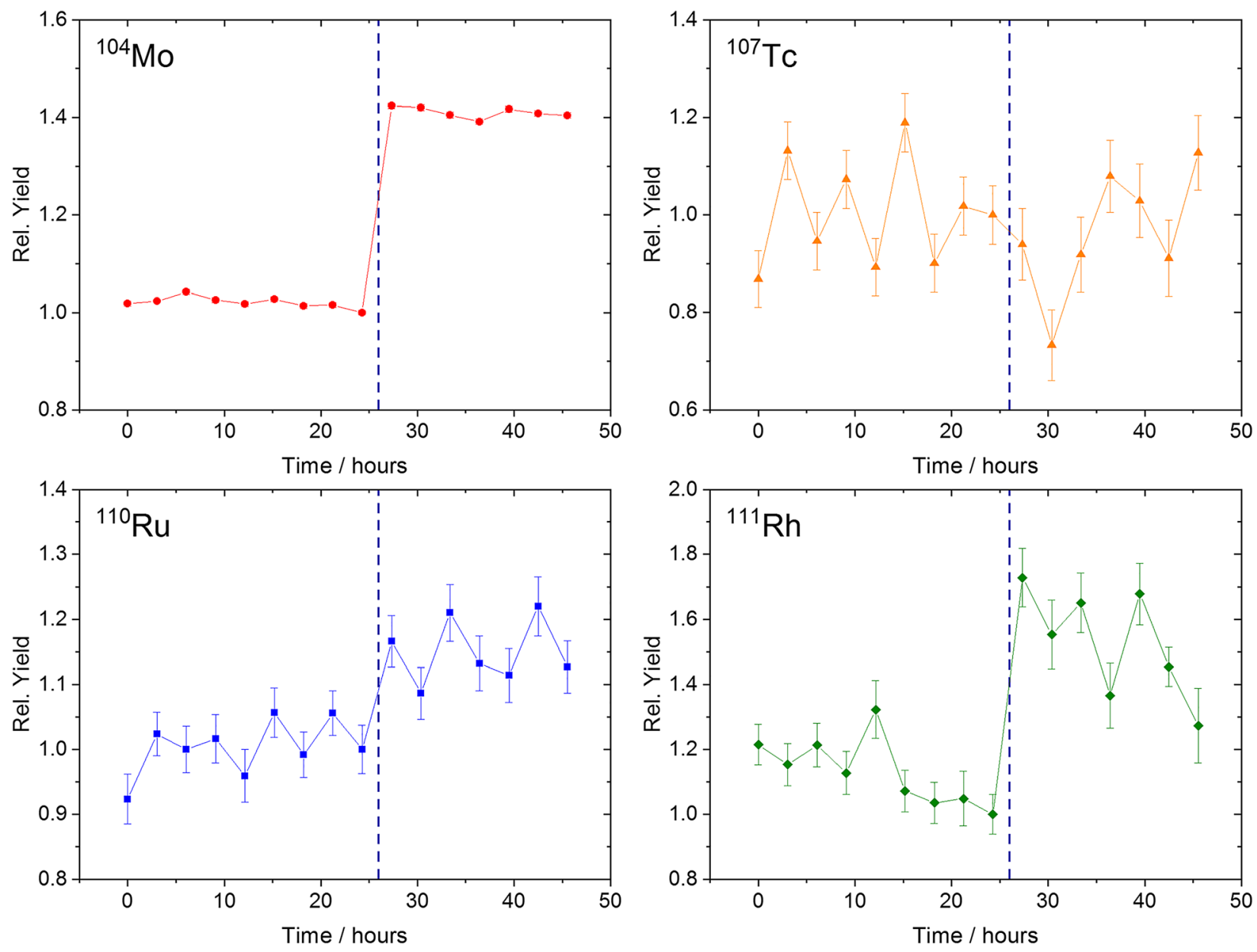

Figure 9: Effect of adding inactive $\operatorname{Re}_{2}(\mathrm{CO})_{10}$ to the process gas. The time of inserting the $\operatorname{Re}_{2}(\mathrm{CO})_{10}$ column at $100^{\circ} \mathrm{C}$ is marked by the dashed blue lines. A Sicapent ${ }^{\mathrm{TM}}$ column was used for purification. FORA was operated using $100 \% \mathrm{CO}$ at 1 bar at a gas flow rate of $1000 \mathrm{~mL} / \mathrm{min}$. The data are normalized to the last yield measured prior to $\operatorname{Re}_{2}(\mathrm{CO})_{10}$ addition. The error bars represent the statistical error of the measurement.

earlier that intense gas purification is increasing the yield for Rh (cf. Figure 5). Instead, the MicroTorr 602F column appears to be more favorable for the formation of MCCs from $\mathrm{Rh}$ than a Ni-column producing $\mathrm{Ni}(\mathrm{CO})_{4}$ as a booster.

As a cross-check of the experiments performed with a $\mathrm{Ni}$-column, it was decided to use an alternate source of $\mathrm{Ni}(\mathrm{CO})_{4}$ for confirmation. A MicroTorr $902 \mathrm{~F}$ purification column is expected to show a similar performance as the freshly reduced Ni-columns usually employed in this study, as it is based on a purification medium containing metallic nickel [28]. No long-term measurements were performed in this case, but as expected, a fast and strong increase in yield was observed for all investigated MCCs of $\mathrm{Mo}, \mathrm{Tc}, \mathrm{Ru}$ and $\mathrm{Rh}$ if the nickel-containing MicroTorr 902F column was introduced to the loop.

The measurements were started directly after filling FORA with fresh process gas. A slightly higher pressure in connection with a slightly lower gas flow rate than usual were chosen, being 1.25 bar and $900 \mathrm{~mL} / \mathrm{min}$. Compared to the measurement with a Sicapent ${ }^{\mathrm{TM}}$ column only, for ${ }^{104} \mathrm{Mo}$ the gain was a factor of 2.8 , for ${ }^{107} \mathrm{Tc}$ a factor of 2.2 for ${ }^{110} \mathrm{Ru}$ a factor of 3.2, and for ${ }^{111} \mathrm{Rh}$ a slight increase by a factor of 1.3 has been observed.

The data are in agreement with previous measurements using a Ni-column. Aparently, the nickel content in the MicroTorr $902 \mathrm{~F}$ column leads to an increase of the overall yield of MCCs formed by all investigated isotopes. For Mo and $\mathrm{Ru}$, the obtained increase in yield is higher than the one previously obtained (see Figure 10). This could be caused by the slightly higher overall pressure of the process gas [17]. But a MicroTorr 902F column is also expected to show increased yields for the formation of $\mathrm{Ni}(\mathrm{CO})_{4}$, likely due to higher dispersion of nickel, and additionally better gas purification capabilities than the self-made nickel columns. 

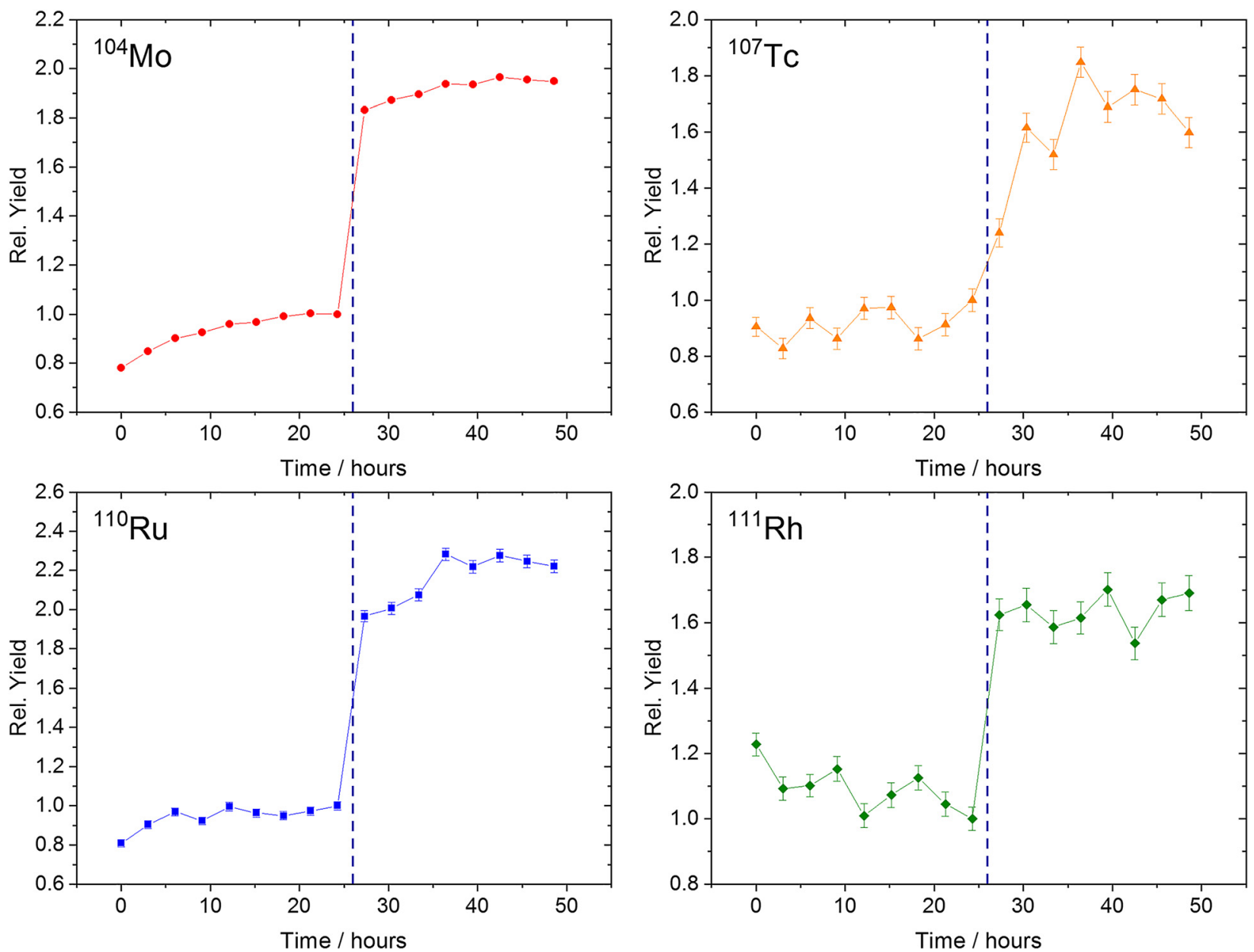

Figure 10: Effect of a Ni-column onto the yield for simultaneously measured volatile Mo, Tc, Ru and Rh compounds. Hundred percent CO at 1 bar at a gas flow of $1000 \mathrm{~mL} / \mathrm{min}$ were used in FORA. Only a Sicapent ${ }^{\mathrm{TM}}$ column was used for purification. The data are normalized to the last yield measured before introducing the Ni-column. The vertical, dashed, blue lines mark the point at which the Ni-column was inserted. The error bars represent the statistical error of the measurement.

\subsubsection{Mass spectrometric analysis}

To elucidate the processes related to the MicroTorr $902 \mathrm{~F}$ cartridge, mass spectroscopic investigations of the process gas were performed. The gas was sampled from two spots: Right in front of the reaction chamber, monitoring the gas available for reaction and right after the charcoal trap, monitoring the gas after being filtered by the charcoal trap.

As expected, the use of CO-gas in conjunction with the MicroTorr $902 \mathrm{~F}$ column leads to the formation of $\mathrm{Ni}(\mathrm{CO})_{4}$. The corresponding species are visible in the mass spectra shown in Figure 12. $\mathrm{Ni}(\mathrm{CO})_{4}$ was detected in front of the reaction chamber as well as after the charcoal trap, indicating that macro amounts of $\mathrm{Ni}(\mathrm{CO})_{4}$ are indeed not completely retained by the charcoal trap. The spectrum shown on the right side of Figure 12 allows identifying naturally occurring isotopes of nickel as well as the fragments $\mathrm{Ni}(\mathrm{CO})_{1}, \mathrm{Ni}(\mathrm{CO})_{2}$ and $\mathrm{Ni}(\mathrm{CO})_{3}$. Additionally, ${ }^{56} \mathrm{Fe}$ is visible in the mass spectrum, indicating the formation of $\mathrm{Fe}(\mathrm{CO})_{5}$ in the process gas as well.

Additional mass spectra were measured in front of the reaction chamber with a MicroTorr $602 \mathrm{~F}$ purification column being used (see Figure 13). As expected, $\mathrm{Ni}(\mathrm{CO})_{4}$ or $\mathrm{Fe}(\mathrm{CO})_{5}$ could not be detected under these conditions as well as $\mathrm{O}_{2}$. Note here again, that the ${ }^{111} \mathrm{Rh}$ carbonly formation was very sensitive towards traces of oxygen. Thus, this purification column, which removes efficiently oxygen, was always shown to increase the formation and transport yields of ${ }^{111} \mathrm{Rh}$ carbonyl.

The mass spectrometry data presented are in complete agreement with relating the booster effect observed for $\mathrm{Ni}$ columns to the formation of $\mathrm{Ni}(\mathrm{CO})_{4}$. Figure 11 reveals that 

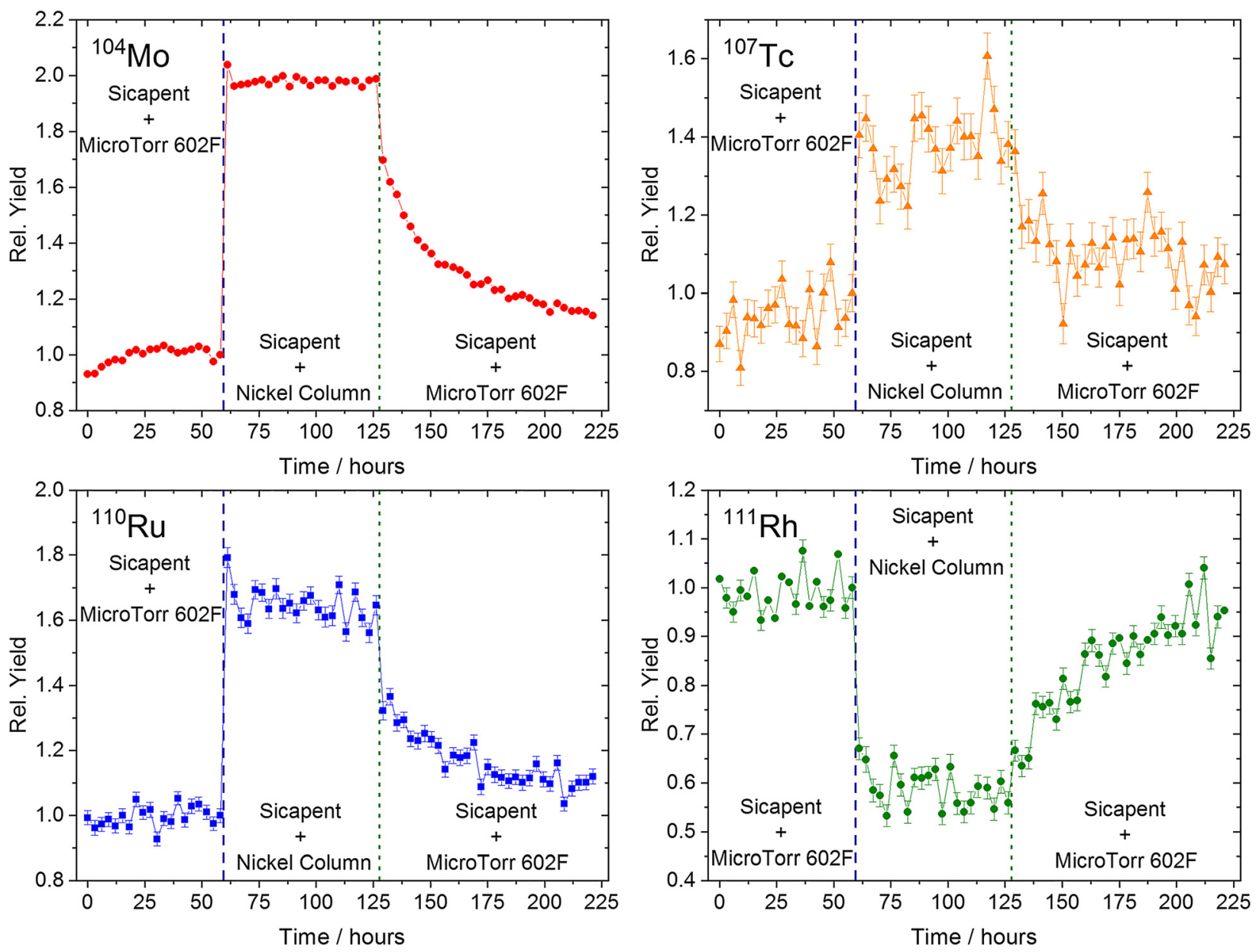

Figure 11: Long-term measurement series with different columns being introduced into the process gas loop of FORA. FORA was operated with $100 \% \mathrm{CO}$ at 1.00 bar at a gas flow rate of $1000 \mathrm{~mL} / \mathrm{min}$. A Sicapent ${ }^{\mathrm{TM}}$ cartridge was online during the entire measurement series. Initially, an additional MicroTorr $602 \mathrm{~F}$ column was online as well. The measurement series was immediately started after filling the FORA-system with fresh process gas. Blue dashed line: Exchange of the initial MicroTorr $602 \mathrm{~F}$ cartridge with a freshly reduced Ni-column. Green dotted line: Exchange of the Ni-column with the previous MicroTorr $602 \mathrm{~F}$ cartridge. The data are normalized to the yield measured before insertion of the $\mathrm{Ni}$-column. The error bars represent the statistical error of each measurement.

the booster effect upon addition of a Ni-column can indeed be slowly eliminated by replacing the $\mathrm{Ni}$-column with a MicroTorr $602 \mathrm{~F}$ purification cartridge which acts as a $\mathrm{Ni}(\mathrm{CO})_{4}$ trap. The MicroTorr $602 \mathrm{~F}$ cartridge was confirmed to remove MCCs from the process gas [27]. The increase in yield induced by the addition of a Ni-column is therefore assumed to be indeed caused by the formation of $\mathrm{Ni}(\mathrm{CO})_{4}$. It is likely that the oxygen-gettering capabilities of freshly reduced nickel are increasing the effect. Nevertheless, it must be considered that the MicroTorr $602 \mathrm{~F}$ column is actually very efficient at removing impurities from the process gas as well. The data shown in Figure 5 reveal that the MircoTorr 602F actually lowers the yield for the formation of radioactive MCCs. The purification capabilities of reduced nickel are unlikely massively superior to the ones of a MicroTorr $602 \mathrm{~F}$ cartridge, which would be a necessary condition to explain the opposite effect of the two columns based on purification only. The booster effect of a Nicolumn can therefore be clearly assigned to the formation of $\mathrm{Ni}(\mathrm{CO})_{4}$.

A MicroTorr $902 \mathrm{~F}$ purification column, which is based on a nickel containing medium, showed the same effect as the self-made pure Ni-columns. Both columns are expected to release $\mathrm{Ni}(\mathrm{CO})_{4}$ upon contact with $\mathrm{CO}$. Additionally, the MicroTorr 902F purification column removes trace amounts of water and oxygen. The mass spectra in Figure 12 confirm the formation of $\mathrm{Ni}(\mathrm{CO})_{4}$. The signal assigned to ${ }^{56} \mathrm{Fe}$ might indicate the formation of $\mathrm{Fe}(\mathrm{CO})_{5}$ as well in the FORA-setup. The peaks corresponding to inactive MCCs are vanishing upon addition of a MicroTorr 602F column, which is in 

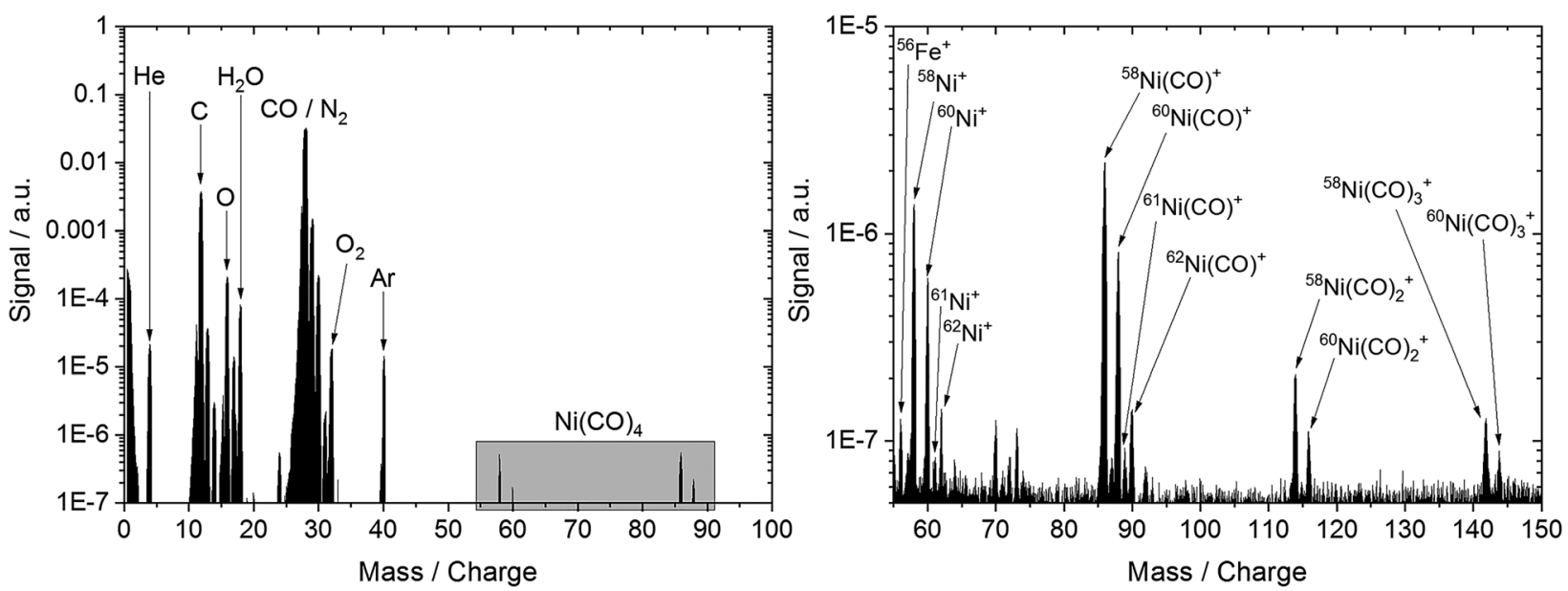

Figure 12: Mass spectra measured in $100 \% \mathrm{CO}$ with a MicroTorr $902 \mathrm{~F}$ column inserted into the gas stream. Both mass spectra were recorded in front of the reaction chamber. Left: Complete mass spectrum showing the peaks from CO as well as gas impurities. Note that the spectra can only be qualitatively evaluated with the method used here. Right: Mass spectrum focusing onto the region where $\mathrm{Ni}(\mathrm{CO})_{4}$ was observed. The MS parameters were optimized for measuring $\mathrm{Ni}(\mathrm{CO})_{4}$. The peaks associated with inactive MCCs are labeled.

agreement with assigning the reduction of yield upon intense gas purification to the removal of inactive MCCs from the process gas.

\subsubsection{Isothermal chromatography}

External chromatograms were measured by inserting a 2.4 m-long quartz column into the FORA setup, which was cooled to different temperatures. The results for all four investigated elements are shown in Figure 14.

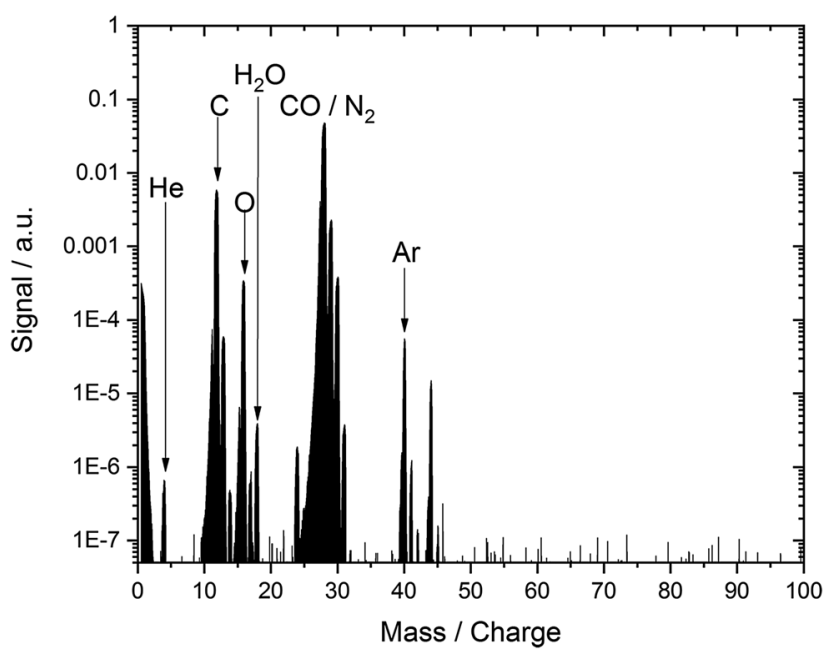

Figure 13: Mass spectrum measured in $100 \%$ CO with a MicroTorr $602 \mathrm{~F}$ column online for intense gas purification.
The results obtained for ${ }^{104} \mathrm{Mo}(\mathrm{CO})_{6}$ are of higher quality due to the high stability of the formed complex and confirm the booster observations made previously in the FORA loop. Note that during the IC experiments the water trace content in the reaction gas was never as low and controlled as in the FORA experiments without the IC-column. Therefore, the absolute yields for Tc, Ru and Rh were generally much lower than at optimum conditions, which explains also the scatter of the data (see Figure 14). It even appears, that the yields for Tc, $\mathrm{Ru}$ and $\mathrm{Rh}$ are higher while using a MicroTorr $602 \mathrm{~F}$ column, due to its cleaning capacity, compared to the $\mathrm{Ni}(\mathrm{CO})_{4}$-booster. However, these experiments were only intended to reveal different volatile MCC species formed, when adding the yield-boosting $\mathrm{Ni}(\mathrm{CO})_{4}$. Therefore, the normalized external chromatogram shall be used to identify various species by their different interactions with the quartz surfaces, as shown in Figure 15.

The obtained isothermal chromatography adsorption data with and without Ni-column (Figure 15) are with the given uncertainties in agreement for Mo. The same volatile species is produced in purified $\mathrm{CO}$ as well as $\mathrm{CO}$ with added $\mathrm{Ni}(\mathrm{CO})_{4}$. It appears that under both conditions only one species is produced. For ${ }^{104} \mathrm{Mo}$ it is likely $\mathrm{Mo}(\mathrm{CO})_{6}$, since the obtained gas chromatography data are in agreement with the adsorption enthalpy determined by $[8]$ for $\mathrm{Mo}(\mathrm{CO})_{6}$ on quartz. It is concluded that upon addition of $\mathrm{Ni}(\mathrm{CO})_{4}$ to the process gas, Mo produced by the spontaneous fission of ${ }^{252} \mathrm{Cf}$ is still forming $\mathrm{Mo}(\mathrm{CO})_{6}$ and it is still transported as such to the charcoal trap. Differences are observed for 

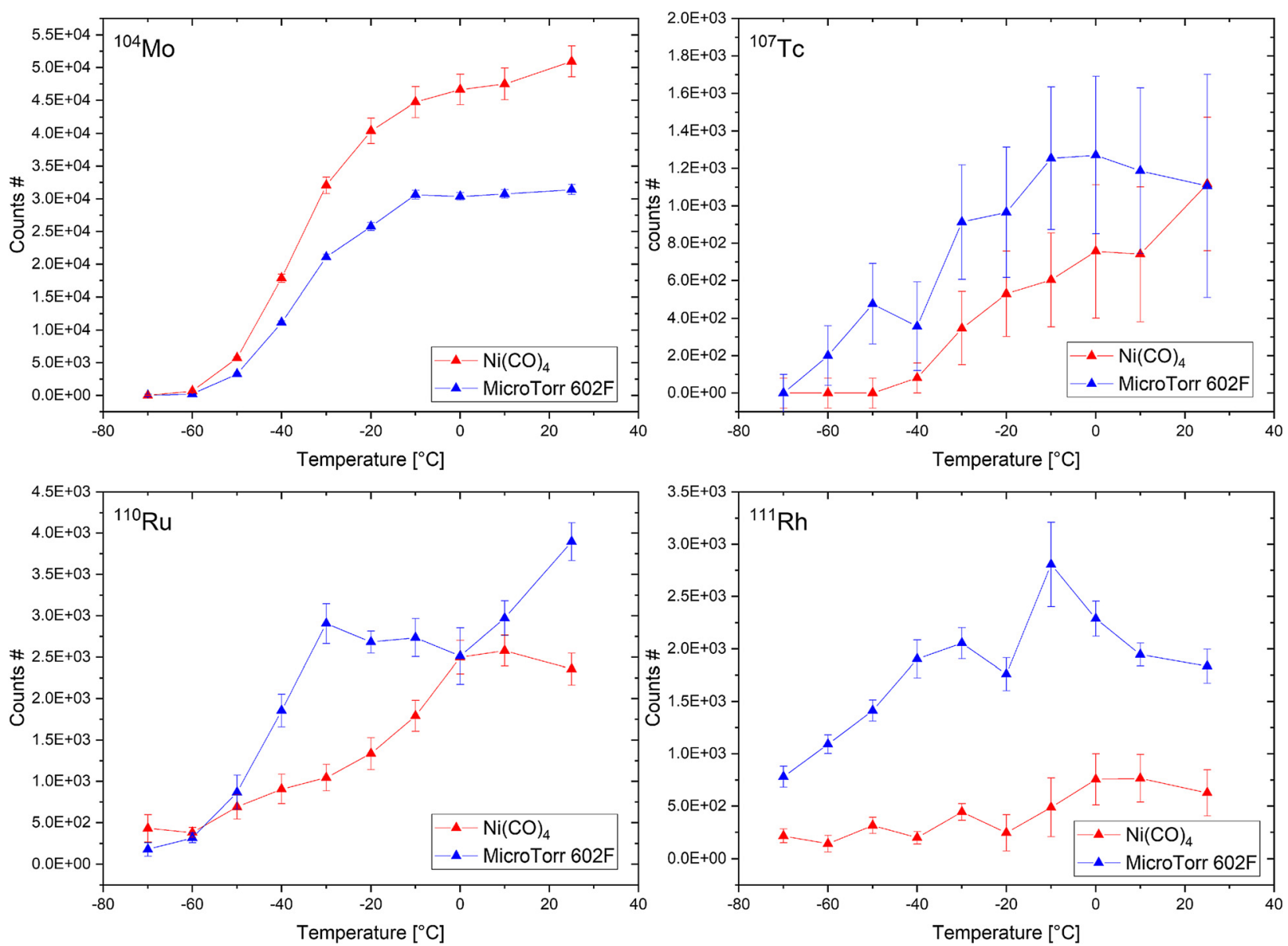

Figure 14: Data obtained during IC investigations for all four investigated elements. The red dots correspond to measurements with a $\mathrm{Ni}$ column while the blue triangles correspond to measurements with a MicroTorr $602 \mathrm{~F}$ cartridge. The data correspond to count numbers accumulated for each isotope in the gamma spectra simultaneously measured at identical measuring times for each temperature. The error bars represent the absolute uncertainty of each measurement deduced from the integration of the gamma sectra.

${ }^{105} \mathrm{Tc},{ }^{110} \mathrm{Ru}$, and ${ }^{111} \mathrm{Rh}$. They might indicate the formation of a species with a lower volatility when the $\mathrm{Ni}(\mathrm{CO})_{4}$ is present in the carrier gas. Experimental values for the adsorption enthalpy of $\mathrm{Tc}(\mathrm{CO})_{n}$ and $\mathrm{Ru}(\mathrm{CO})_{5}$ on quartz are available $[9,16]$. In these reference experiments the presence of inactive carbonyls was excluded by avoiding steel surfaces in contact with the $\mathrm{CO}$ containing gas. The simulation results using the literature values for the adsorption enthalpies of carbonyl species of Tc and Ru on quartz surfaces are shown in Figure 15. They agree within the uncertainty limits given in literature with the data obtained for ${ }^{105} \mathrm{Tc}$ in this work. The $\mathrm{Ni}(\mathrm{CO})_{4}$ addition does not significantly shift the adsorption properties for the ${ }^{105} \mathrm{Tc}$ species to conclude a different chemical species. There is however, a deviation for the data obtained for ${ }^{110} \mathrm{Ru}$. There can be only two reasons given for this observation. Either the chromatography surface quartz is modified slightly by the $\mathrm{Ni}(\mathrm{CO})_{4}$ adsorption, towards which $\mathrm{Ru}(\mathrm{CO})_{5}$ adsorption is sensitive and not sensitive for $\mathrm{Tc}(\mathrm{CO})_{n}$ and $\mathrm{Mo}(\mathrm{CO})_{6}$. Or the formation of mixed complexes is leading to transport and deposition phenomena not included in the simulation. For ${ }^{111} \mathrm{Rh}$, the results indicate that $\mathrm{Ni}(\mathrm{CO})_{4}$ addition influences the adsorption properties of the Rh species on quartz or that even a new species with a lower volatility is formed upon addition of $\mathrm{Ni}(\mathrm{CO})_{4}$. Dedicated experiments will have to be performed with improved counting statistics and 

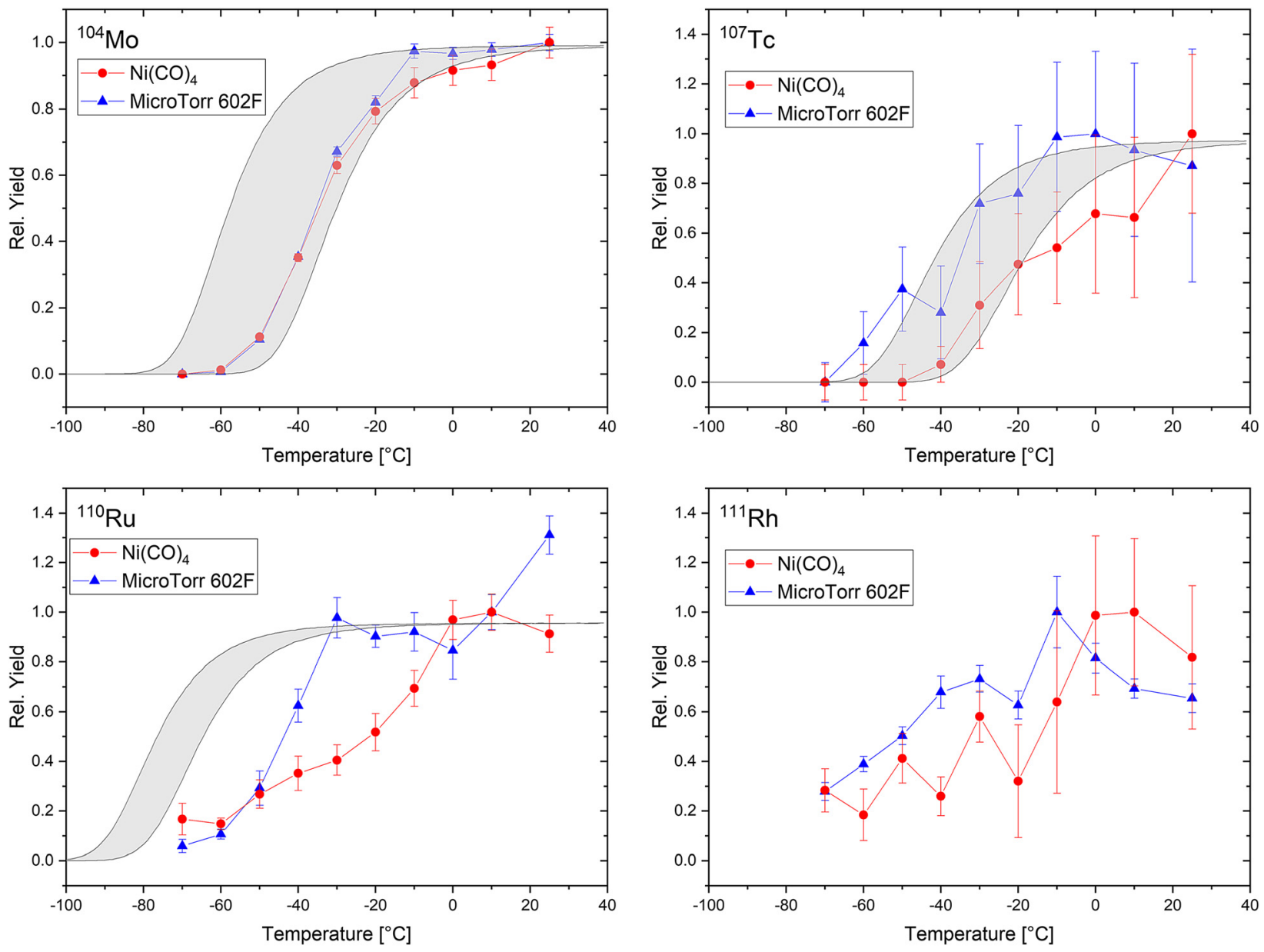

Figure 15: External Chromatograms deduced from the IC investigation of volatile species produced in the FORA setup with and without Nicolumn. The red dots correspond to measurements with a Ni-column while the blue triangles correspond to measurements with a MicroTorr $602 \mathrm{~F}$ cartridge. The grey area shown for ${ }^{104} \mathrm{Mo}$ corresponds to an adsorption enthalpy of $42.5 \pm 2.5 \mathrm{~kJ} / \mathrm{mol}$ as determined by [8] for Mo(CO) 6 . For ${ }^{107} \mathrm{Tc}$, the grey area corresponds to an adsorption enthalpy of $43 \pm 2 \mathrm{~kJ} / \mathrm{mol}$ corresponding to $\mathrm{Tc}(\mathrm{CO})_{n}[16]$ and for ${ }^{110} \mathrm{Ru}$, it corresponds to an adsoprtion enthalpy of $35 \pm 1 \mathrm{~kJ} / \mathrm{mol}$ corresponding to $\mathrm{Ru}(\mathrm{CO})_{5}$ [9]. The error bars represent the propagated uncertainty of each measurement.

reproducibility as well as with a controlled variable inactive MCC contents in the carrier gas. This was beyond the current work.

\subsubsection{Maximum yield determination}

The maximum achievable formation and transport yields for volatile Mo, Tc, Ru and Rh species under well optimized conditions with FORA were measured once with a MicroTorr $602 \mathrm{~F}$ cartridge and once with a Ni-column. The results are shown in Figure 16.

As expected, the obtained yields for Mo and Ru compounds are much higher if a Ni-column is used. For $\mathrm{Ru}$, the yield increase corresponds to about a factor of two, for Mo a gain in yield of about 1.6 is achieved. For Tc, the gain amounts to a factor of about 1.75 . The yield for $\mathrm{Rh}$ was not improved by using a Ni-column under this conditions.

\subsection{General discussion}

\subsubsection{Excluding aerosol-based transport}

Particularly, for this discussion using macroscopic condensable components in the carrier gas it is important to look at the possible accidental aerosol formation upon adding macro amounts of inactive MCCs to the FORA-setup. All emitted ${ }^{252} \mathrm{Cf}$ fission products might adsorb to potentially added aerosol particles, using them as particle gas-jet vehicles for their transport to the 

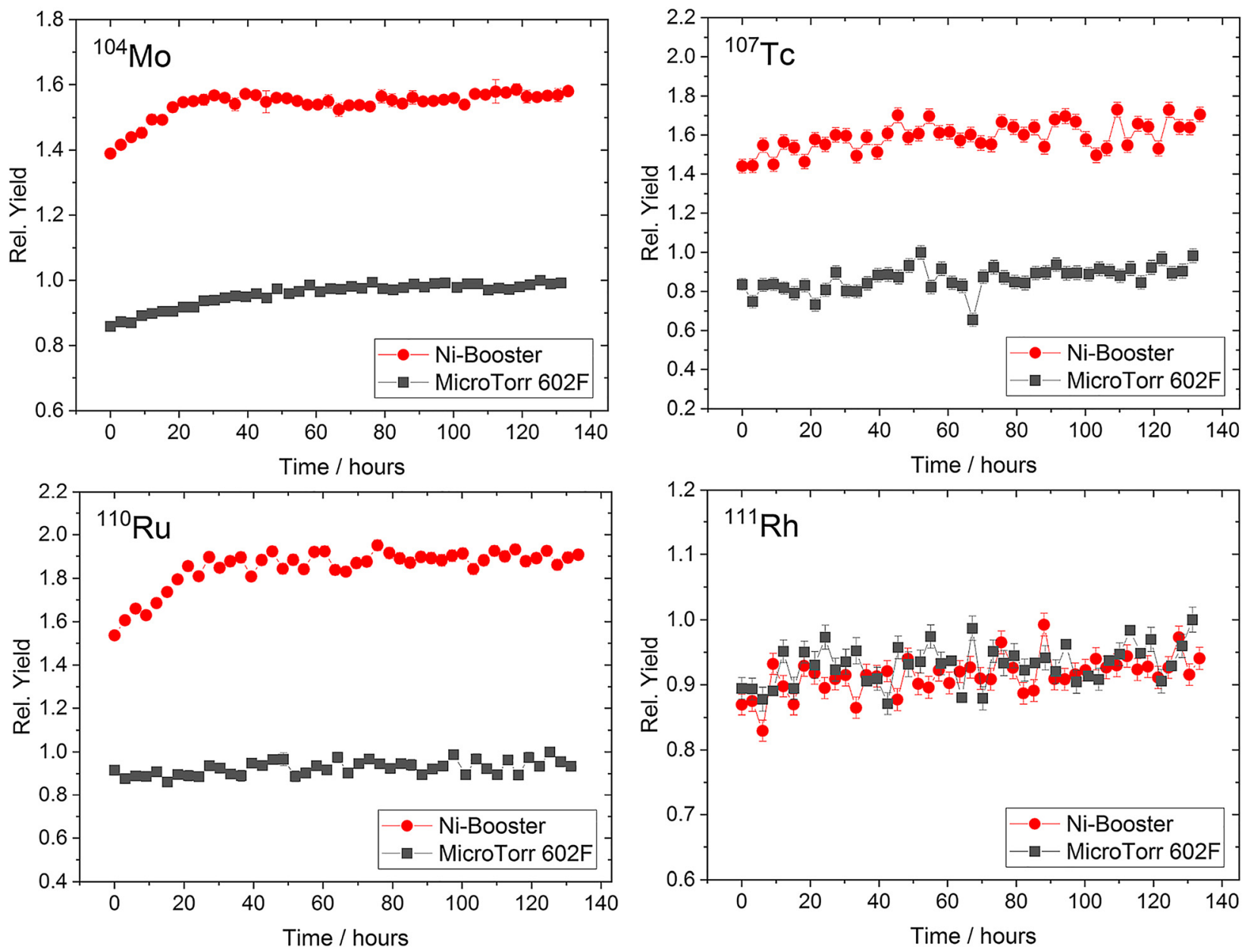

Figure 16: Measurement series performed under optimized reaction conditions as determined in recent studies [17]. MCC yields obtained for two different process gas treatments are compared. Process gas, pressure and gas flow rate were the same for both measurement series (see experimental section). Grey squares: Data points measured using a Sicapent ${ }^{\mathrm{TM}}$ column and a MicroTorr $602 \mathrm{~F}$ cartridge for intense gas purification. Red circles: Data obtained for using a Sicapent ${ }^{\mathrm{TM}}$ column and a Ni-column yielding both gas purification and addition of $\mathrm{Ni}(\mathrm{CO})_{4}$. The data are normalized to the highest yield obtained for using a Sicapent ${ }^{\mathrm{TM}}$ and a MicroTorr $602 \mathrm{~F}$ purification cartridge. The error bars represent the statistical error of each measurement.

charcoal trap. Transport mechanisms based on aerosols were used in multiple studies in the past and proved to be effective $[1,2,4]$. This pathway can be excluded for the observed transport for Mo, Tc, Ru and Rh based on the following simple comparison.

Differentiating between aerosol based transport mechanisms and formation of volatile compounds can be achieved by comparing the $\gamma$-spectra obtained under different conditions. Figure 17 compares a spectrum obtained effectively using $\mathrm{C}$-aerosol based transport with spectra obtained using intense gas purification (Sicapent ${ }^{\mathrm{TM}}$ and MicroTorr $602 \mathrm{~F}$ ) and using a Sicapent ${ }^{\mathrm{TM}}$ and Nicolumn. The spectrum obtained using the $\mathrm{C}$-aerosol gas-jet is an older reference measurement from the same ${ }^{252} \mathrm{Cf}$ source mounted in the Miss Piggy setup described in [31].
The Aerosol spectrum was measured for $7600 \mathrm{~s}$ at a gas flow rate of $1500 \mathrm{~mL} / \mathrm{min}$. For comparison reasons the spectra were normalized.

Contrary to transport based on synthesizing volatile species, aerosol based transport is non-specific and therefore it transports all fission products produced by spontaneous fission of ${ }^{252} \mathrm{Cf}$ as depicted in Figure 17. This results in $\gamma$-spectra that are easily distinguishable from the ones obtained transporting only volatile species. Spectra obtained using $\mathrm{Ni}(\mathrm{CO})_{4}, \mathrm{Fe}(\mathrm{CO})_{5}, \mathrm{Mo}(\mathrm{CO})_{6}$ and $\mathrm{Re}_{2}(\mathrm{CO})_{10}$ (see supporting information) are missing various isotopes well visible in spectra obtained employing aerosol-based transport. The indicated missing isotopes are non-volatile elements without a volatile precursor (e.g., ${ }^{99,101} \mathrm{Nb}$ ) or with a high independent fission yield (e.g., $\left.{ }^{144} \mathrm{Ba}\right)$. It is therefore 


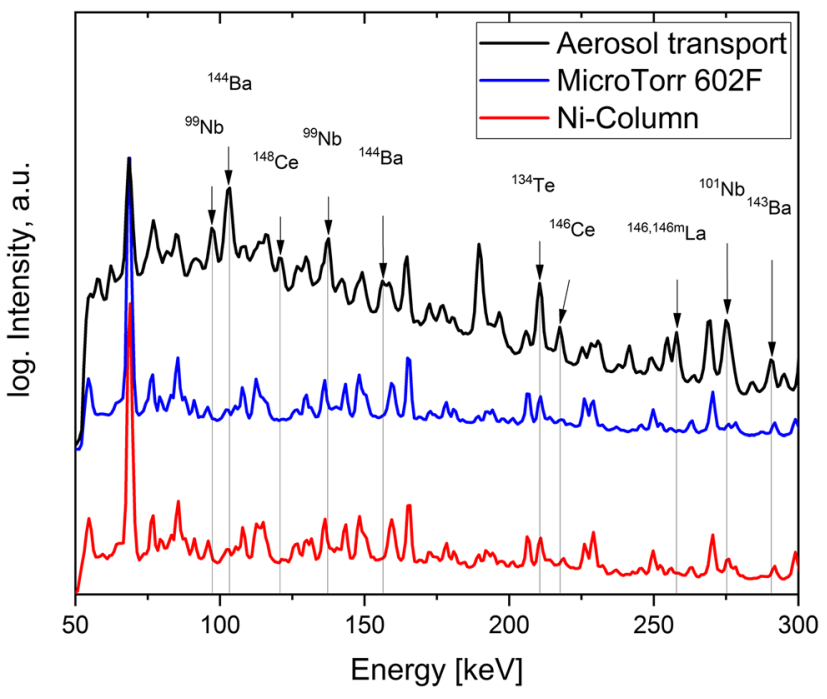

Figure 17: Qualitative comparison of $\gamma$-spectra obtained at three experimental conditions. From top to bottom: Reference spectrum using Miss Piggy and C-aerosols to transport fission products (black, top); FORA-spectrum obtained using a Sicapent ${ }^{\mathrm{TM}}$ and MicroTorr $602 \mathrm{~F}$ cartridge for gas purification (blue, middle); FORA-spectrum using a Sicapent ${ }^{\mathrm{TM}}$ and nickel column (red, bottom). A selection of fission products characteristic for the measured aerosol based spectrum are assigned to their corresponding peaks (see text). The data are shown in a logarithmic scale.

concluded that the increase in Mo, Tc, $\mathrm{Ru}$ and $\mathrm{Rh}$ signal using FORA and introducing inactive MCCs is not caused by accidental aerosol-bound transport, but indeed by an increase of formation and transport of MCCs. Note that many of the peaks solely visible in aerosol based spectra are still assignable to volatile or MCC forming isotopes, which are however also transported using aerosol particles. The corresponding peaks were not assigned in Figure 17 to maintain clarity.

\subsubsection{Tentative reaction mechanism}

The IC data are very encouraging for future studies using carbonyl boosters for the efficient synthesis of MCCs under single-atom chemistry conditions. The current IC based investigation suggests the production of MCCs upon interaction of inactive MCCs with single metal atoms in the gas-phase. A reaction mechanism based on the exchange of CO-ligands can be proposed to superimpose the production by simple $\mathrm{CO}$ capture from the gas phase. The mechanism exemplifying the formation of $\mathrm{Mo}(\mathrm{CO})_{6}$ is shown in Figure 18. Similar mechanisms are expected for the formation of Tc-MCCs, $\mathrm{Ru}(\mathrm{CO})_{5}$ and Rh-MCCs as well as for the usage of different boosters like e.g. $\mathrm{Fe}(\mathrm{CO})_{5}$.

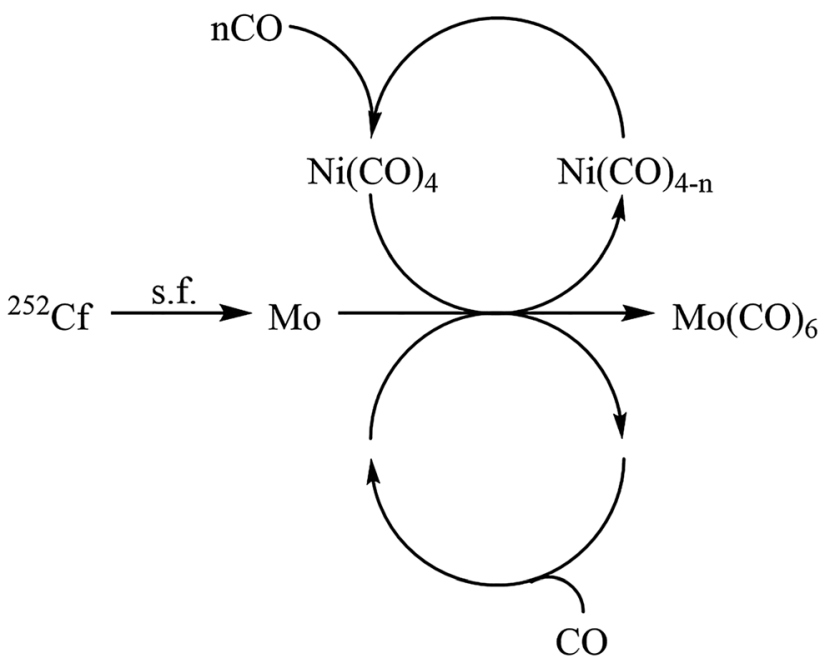

Figure 18: Suggested, generalized mechanism for the action of carbonyl boosters. The mechanism is shown for the specific reaction between $\mathrm{Ni}(\mathrm{CO})_{4}$ and $\mathrm{Mo}$, but is assumed to be similar for the other fission product, the yields of which were boosted by macro amounts of MCCs. s.f. stands for spontaneous fission.

The exchange of one or multiple CO-ligands from inactive MCCs to metal atoms after their production by spontaneous fission is likely boosting the formation yields. A single $\mathrm{Ni}(\mathrm{CO})_{4}$ complex does not contain enough CO-ligands to form for example $\mathrm{Mo}(\mathrm{CO})_{6}$. Therefore, even a follow-up reaction with additional inactive MCCs or CO from the gas-phase is necessary. Unfortunately, no estimation of the number of ligands being exchanged by this mechanism can be made. The formation of an intermediate mixed metal carbonyl complex [32] cannot be excluded as well. The booster effect is presumably mostly caused by impacting the initial formation of radioactive MCCs while the transport is not largely impacted. Note that in a CO atmosphere, the action of inactive MCCs can be assumed to be catalytic, as inactive MCCs might be regenerated (see Figure 18).

The actual mechanism of radioactive MCC formation is expected to be very complex. The data in Figure 8 suggest that MCCs might show even an autocatalytic character, as inactive $\mathrm{Mo}(\mathrm{CO})_{6}$ increases the formation of radioactive ${ }^{104} \mathrm{Mo}(\mathrm{CO})_{6}$. This might be important for volatilization effects in radioactive waste. It is not clear if the booster effect only affects metal atoms being thermalized in the gasphase or if the formation of MCCs from, e.g., transition metal components of steel will also be increased. In the latter case, addition of a booster to the process gas could cause the formation of various MCCs from steel and from impurities in the charcoal trap, e.g., $\mathrm{Cr}(\mathrm{CO})_{6}$. These MCCs show potentially booster activities as well. 
Table 2: Combined, absolute chemical formation and transport yields calculated from the data shown in Figure 16.

\begin{tabular}{lrr}
\hline Isotope & Yield without booster/\% & Yield with booster/\% \\
\hline${ }^{104} \mathrm{Mo}$ & $79 \pm 21$ & $126 \pm 33$ \\
${ }^{107} \mathrm{Tc}$ & $16 \pm 4$ & $28 \pm 6$ \\
${ }^{110} \mathrm{Ru}$ & $40 \pm 19$ & $82 \pm 40$ \\
${ }^{111} \mathrm{Rh}$ & $24 \pm 4$ & $23 \pm 4$ \\
\hline
\end{tabular}

The method of calculation is described in the supporting information. The large standard deviations are caused by uncertainties related to fission yields and $\gamma$-branching ratios required for the calculations.

In macrochemistry, there are actually a few examples where MCCs of one kind were used to synthesize MCCs of another. An example is the synthesis of $\mathrm{Mo}(\mathrm{CO})_{6}$ or $\mathrm{W}(\mathrm{CO})_{6}$ from heating a mixture of $\mathrm{MoCl}_{6} / \mathrm{WCl}_{6}$ and $\mathrm{Fe}(\mathrm{CO})_{5}$ in ether [33]. Another example is the synthesis of $\mathrm{Mo}(\mathrm{CO})_{6}$ from fission products by mixing $\mathrm{U}_{3} \mathrm{O}_{8}$ with $\mathrm{Cr}(\mathrm{CO})_{6}$ prior to bombarding the mixture with neutrons [34].

\subsubsection{The optimum conditions}

With the data shown in Figure 16 and using a method based on determining the spontaneous fission activity of the used

${ }^{252} \mathrm{Cf}$-source in separate measurements with catcher foils, the overall absolute yield for each investigated species was determined. Nuclear data from [35] and the equation for a radioactive decay equilibrium given in [36] were used. A full description of the method is given in the supporting information. Cumulative fission yields were used for the calculations. The results are given in Table 2 . Note that the yields given here are absolute yields.

Despite the large uncertainties associated with the calculation method, the data in Table 2 give an idea about the maximum achievable yields for each investigated element using FORA. For discussion, it is referred to the lower limits of the calculated yields. For Mo, excellent yields $>93 \%$ can be obtained while for $\mathrm{Ru}$, yields likely larger than $42 \%$ were reached. For Tc and $\mathrm{Rh}$, yields around $20 \%$ were obtained only, despite reaction parameter optimization and usage of a booster.

It is important to emphasize that the large uncertainties associated with the calculation of absolute yields in the FORA-setup are not caused by the quality of the measured data shown here, but by the uncertainties related to the literature values needed for calculation. For example, the $y$-branching ratio for the investigated peak of ${ }^{104} \mathrm{Mo}$ at $68.8 \mathrm{keV}$ is associated with a relative error of $23.6 \%$ according to [35]. During error propagation, these uncertainties of the reference values cause the large standard deviations shown in Table 2. This is also the reason, why relative yields are given for most measurements presented here instead of absolute yields. The large error bars caused by the uncertainties of the literature values would strongly diminish the quality of the experimental results.

\section{Conclusion}

In this study we have demonstrated that inactive carbonyls boost the formation of other carbonyls already at low levels (below estimated $10 \mathrm{ppm}$ ) produced in $\mathrm{CO}$ atmospheres by the operation in setups containing steel components. Using the FORA system it was shown that upon addition of inactive MCC's to the carrier gas up to concentrations of $1000 \mathrm{ppm}$ a strongly increasing yield was observed for MCCs formed by the fission products Mo, Tc, Ru and Rh. The use of $\mathrm{Ni}(\mathrm{CO})_{4}$ resulted in about a factor of two higher absolute yields for Mo and Ru. The MCC formation of Tc appears to be least affected. For Rh-MCCs, the situation is more complicated due to their higher sensitivity towards impurities. A dedicated gas purification procedure has to be developed, which does not influence the booster content in the gas phase. The sensitivity of each investigated species towards the impurities relevant for this study are summarized in Table 3.

Table 3: Summary concerning the impact of all impurities relevant for this study onto the overall yields of the chemical species investigated.

\begin{tabular}{lrrrrr}
\hline Species/impurity & $\mathrm{Fe}(\mathrm{CO})_{5}$ & $\mathrm{Mo}_{\mathbf{C}}(\mathrm{CO})_{\mathbf{6}}$ & $\mathbf{R e}_{\mathbf{2}}(\mathrm{CO})_{\mathbf{1 0}}$ & $\mathbf{N i ( C O ) _ { \mathbf { 4 } }}$ & $\mathbf{O}_{\mathbf{2}}$ \\
\hline${ }^{104} \mathrm{Mo}(\mathrm{CO})_{6}$ & + & + & + & + & - \\
${ }^{107} \mathrm{Tc}(\mathrm{CO})_{n}$ & $=$ & $=$ & $=$ & + & - \\
${ }^{110} \mathrm{Ru}(\mathrm{CO})_{5}$ & + & + & + & + & - \\
${ }^{111} \mathrm{Rh}(\mathrm{CO})_{m}$ & + & $=$ & + & - \\
\hline
\end{tabular}

The data shown for $\mathrm{O}_{2}$ and $\mathrm{H}_{2} \mathrm{O}$ are taken from [17]. For this table, it is assumed that the investigated isotopes form metal carbonyl species. A " + " denotes a positive correlation, meaning that addition of the corresponding impurity was shown to increase the yield for the investigated species. A "-" denotes a negative correlation, meaning that addition of the corresponding impurity was shown to decrease the yield for the investigated species. A "=" denotes no correlation, therefore no impact of the impurity was found onto the investigated species. For ${ }^{111} \mathrm{Rh}(\mathrm{CO})_{m}$ upon addition of $\mathrm{H}_{2} \mathrm{O}$, the data given in [17] did not allow for a clear conclusion, therefore a "?" is noted for the correlation. 
It is concluded that the inactive MCCs themselves are responsible for the observed increase in yield, with the exception of experiments with $\mathrm{Ni}(\mathrm{CO})_{4}$, where the positive effect was probably a combination of $\mathrm{Ni}(\mathrm{CO})_{4}$ itself and the oxygen/water removal properties of the used freshly reduced Ni-columns and fresh $\mathrm{Ni}$-metal produced in the decomposition of $\mathrm{Ni}(\mathrm{CO})_{4}$ throughout the FORA setup. The presented data suggest that MCC boosters do not change the speciation of the radioactive Mo compound but rather impact its formation yield. For Tc, Ru and Rh the formation of a different $\mathrm{MCC}$ with $\mathrm{Ni}(\mathrm{CO})_{4}$ cannot be excluded.

Otherwise, we would like to note, that the addition of inactive MCCs may cause a number of prohibitive issues for certain experiments, particularly with the lighter transactinides. The addition of $\mathrm{Ni}(\mathrm{CO})_{4}$ to the process gas might cause deposition of nickel on the inner surfaces of the used setups influencing adsorption properties of surfaces. This problem can probably be solved. E.g., in studies targeted at investigating the first bond dissociation energy (FBDE) of $\mathrm{Sg}(\mathrm{CO})_{6}, \mathrm{Ni}(\mathrm{CO})_{4}$ might be useable to increase the formation yield for this compound. Since $\mathrm{Ni}(\mathrm{CO})_{4}$ has a low FBDE (around $105 \mathrm{~kJ} / \mathrm{mol}$ according to [29]) it is expected to thermally decompose at much lower temperatures than $\mathrm{Sg}(\mathrm{CO})_{6}$. Therefore, it might be possible to use a dedicated decomposition oven to selectively remove $\mathrm{Ni}(\mathrm{CO})_{4}$ directly from the transport gas stream after the synthesis of $\mathrm{Sg}(\mathrm{CO})_{6}$ before entering the chromatographic setups.

Author contributions: All the authors have accepted responsibility for the entire content of this submitted manuscript and approved submission.

Research funding: This work was supported by the Swiss National Science Foundation (grant 200021_162769).

Conflict of interest statement: The authors declare no conflicts of interest regarding this article.

\section{References}

1. Türler A., Eichler R., Yakushev A. Chemical studies of elements with $Z \geq 104$ in gas phase. Nucl. Phys. 2015, 944, 640-689.

2. Schädel M. Chemistry of the superheavy elements. Phil. Trans. Roy. Soc. A 2015, 373, 1-15.

3. Eichler R. The periodic table - an experimenter's guide to transactinide chemistry. Radiochim. Acta 2019, 107, 865-877.

4. Türler A., Pershina V. Advances in the production and chemistry of the heaviest elements. Chem. Rev. 2013, 113, 1237-1312.

5. Eichler R., Asai M., Brand H., Chiera N. M., Nitto A. D., Dressler R., Düllmann C. E., Even J., Fangli F., Goetz M., Haba H., Hartmann W., Jäger E., Kaji D., Kanaya J., Kaneya Y., Khuyagbaatar J., Kindler B., Komori Y., Kraus B., Kratz J. V., Krier J., Kudou Y., Kurz N., Miyashita
S., Morimoto K., Morita K., Murakami M., Nagame Y., Ooe K., Piguet D., Sato N., Sato T. K., Steiner J., Steinegger P., Sumita T., Takeyama M., Tanaka K., Tomitsuka T., Toyoshima A., Tsukada K., Türler A., Usoltsev I., Wakabayashi Y., Wang Y., Wiehl N., Wittwer Y., Yakushev A., Yamaki S., Yano S., Yamaki S., Qin Z. Complex chemistry with complex compounds. EPJ Web Conf. 2016, 131, 1-7.

6. Even J., Yakushev A., Düllmann C. E., Haba H., Asai M., Sato T. K., Brand H., Nitto A. D., Eichler R., Fan F. L., Hartmann W., Huang M., Jäger E., Kaji D., Kanaya J., Kaneya Y., Khuyagbaatar J., Kindler B., Kratz J. V., Krier J., Kudou Y., Kurz N., Lommel B., Miyashita S., Morimoto K., Morita K., Murakami M., Nagame Y., Nitsche H., Ooe K., Qin Z., Schädel M., Steiner J., Sumita T., Takeyama M., Tanaka K., Toyoshima A., Tsukada K., Türler A., Usoltsev I., Wakabayashi Y., Wang Y., Wiehl N., Yamaki S. Synthesis and detection of a seaborgium carbonyl complex. Science 2014, 345, 1491-1493.

7. Usoltsev I., Eichler R., Wang Y., Even J., Yakushev A., Haba H., Asai M., Brand H., Nitto A. D., Düllmann C. E., Fangli F., Hartmann W., Huang M., Jäger E., Kaji D., Kanaya J., Kaneya Y., Khuyagbaatar J., Kindler B., Kratz J. V., Krier J., Kudou Y., Kurz N., Lommel B., Miyashita S., Morimoto K., Morita K., Murakami M., Nagame Y., Nitsche H., Ooe K., Sato T. K., Schädel M., Steiner J., Steinegger P., Sumita T., Takeyama M., Tanaka K., Toyoshima A., Tsukada K., Türler A., Wakabayashi Y., Wiehl N., Yamaki S., Qin Z.

Decomposition studies of group 6 hexacarbonyl complexes. Part 1: production and decomposition of $\mathrm{Mo}(\mathrm{CO})_{6}$ and $\mathrm{W}(\mathrm{CO})_{6}$. Radiochim. Acta 2016, 104, 141-151.

8. Even J., Yakushev A., Düllmann C. E., Dvorak J., Eichler R., Gothe O., Hild D., Jäger E., Khuyagbaatar J., Kratz J. V., Krier J., Niewisch L., Nitsche H., Pysmenetska I., Schädel M., Schausten B., Türler A., Wiehl N., Wittwer D. Rapid synthesis of radioactive transitionmetal carbonyl complexes at ambient conditions. Inorg. Chem. 2012, 51, 6431-6433.

9. Wang Y., Qin Z., Fan F. L., Fan F. Y., Cao S. W., Wu X. L., Zhang X., Bai J., Yin X. J., Tian L. L., Zhao L., Tian W., Li Z., Tan C. M., Guo J. S., Gäggeler H. W. Gas-phase chemistry of Mo, Ru, W and Os metal carbonyl complexes. Radiochim. Acta 2014, 102, 69-76.

10. Even J., Yakushev A., Düllmann C. E., Dvorak J., Eichler R., Gothe O., Hartmann W., Hild D., Jäger E., Khuyagbaatar J., Kindler B., Kratz J. V., Krier J., Lommel B., Niewisch L., Nitsche H., Pysmenetska I., Schädel M., Schausten B., Türler A., Wiehl N., Wittwer D. In-situ formation, thermal decomposition, and adsorption studies of transition metal carbonyl complexes with short-lived radioisotopes. Radiochim. Acta 2014, 102, 1093-1110.

11. Pershina V., Iliaš M. Carbonyl compounds of Tc, Re and Bh: electronic structure, bonding and volatility. J. Chem. Phys. 2018, 149, 204306.

12. Iliaš M., Pershina V. Carbonyl compounds of Rh, Ir, and Mt: electronic structure, bonding and volatility. Phys. Chem. Chem. Phys. 2020, 22, 18681-18694.

13. Even J., Ackermann D., Asai M., Block M., Brand H., Nitto A. D., Düllmann C. E., Eichler R., Fan F., Haba H., Hartmann W., Hübner A., Heßberger F. P., Huang M., Jäger E., Kaji D., Kanaya J., Kaneya Y., Khuyagbaatar J., Kindler B., Kratz J. V., Krier J., Kudou Y., Kurz N., Laatiaoui M., Lommel B., Maurer J., Miyashita S., Morimoto K., Morita K., Murakami M., Nagame Y., Nitsche H., Ooe K., Qin Z., Sato T. K., Schädel M., Steiner J., Sumita T., Takeyama M., Tanaka K., Toyoshima A., Tsukada K., Türler A., Usoltsev I., Wakabayashi Y., Wang Y., Wiehl N., 
Yakushev A., Yamaki S. In situ synthesis of volatile carbonyl complexes with short-lived nuclides. J. Radioanal. Nucl. Chem. 2015, 303, 2457-2466.

14. Cao S., Wang Y., Qin Z., Fan F., Haba H., Komori Y., Wu X., Tan C., Zhang $X$. Gas-phase chemistry of ruthenium and rhodium carbonyl complexes. Phys. Chem. Chem. Phys. 2016, 18, 119-125.

15. Wang Y., Cao S., Zhang J., Fan F., Yang J., Haba H., Komori Y., Yokokita T., Morimoto K., Kaji D., Wittwer Y., Eichler R., Türler A., Qin Z. The study of rhenium pentacarbonyl complexes using single-atom chemistry in the gas phase. Phys. Chem. Chem. Phys. 2019, 21, 7147-7154.

16. Wang Y., Qin Z., Fan F. L., Haba H., Komori Y., Cao S. W., Wu X. L., Tan C. M. Gas-phase chemistry of technetium carbonyl complexes. Phys. Chem. Chem. Phys. 2015, 17, 13288-13234.

17. Wittwer Y., Eichler R., Herrmann D., Türler A. The influence of chemical parameters on the in-situ metal carbonyl complex formation studied with the Fast On-line Reaction Apparatus (FORA). Radiochim. Acta 2021, 109, 243-260.

18. Miroslavov A. E., Gorshkov N. I., Lumpov A. L., Yalfimov A. N., Suglobov D. N., Ellis B. L., Braddock R., Smith A. M., Prescott M. C., Lawson R. S., Sharma H. L. Evaluation of ${ }^{99 \mathrm{~m}} \mathrm{Tc}(\mathrm{CO})_{5} \mathrm{I}$ as a potential lung perfusion agent. Nucl. Med. Biol. 2009, 36, 73-79.

19. Wareham L. K., Poole R. K., Tinajero-Trejo M. CO-releasing metal carbonyl compounds as antimicrobial agents in the postantibiotic era. J. Biol. Chem. 2015, 290, 18999-19007.

20. Schlawe D., Majdalani A., Velcicky J., Heißler E., Wieder T., Prokop A., Schmalz H. G. Eisenhaltige Nucleosidanaloga mit apoptoseinduzierender Wirksamkeit. Angew. Chem. 2004, 116, 1763-1766.

21. Johnson T. R., Mann B. E., Clark J. E., Foresti R., Green C. J., Motterlini R. Metal carbonyls: a new class of pharmaceuticals? Angew. Chem. Int. Ed. 2003, 42, 3722-3729.

22. Lukens W. W., Shuh D. K., Schroeder N. C., Ashley K. R. Identification of the non-pertechnetate species in hanford waste tanks, Tc(I)-Carbonyl complexes. Environ. Sci. Technol. 2004, 38 , 229-233.

23. Ballof J., Seiffert C., Crepieux B., Ramos J. P., Rothe S., Stora T., Düllmann C. E. Volatile Carbonyl Compounds for New Radioactive Ion Beams at ISOLDE; TASCA17 Conference Abstract: Germany, 2017.

24. Ballof J., Seiffert C., Stora T., Düllmann C. E., Yakushev A. Refractory beams at Isotope Separator On Line DEvice (ISOLDE) - a concept for a fission recoil target. In 6 Workshop on Nuclear Fission and Spectroscopy of Neutron-Rich Nuclei; ILL - Institut Laue-Langevin: Grenoble, France, 1429, 2017; pp. 643-646.

25. Wittwer Y., Eichler R., Herrmann D., Türler A. The influence of physical parameters on the in-situ metal carbonyl complex formation studied with the Fast On-line Reaction Apparatus (FORA). Radiochim. Acta 2021, 109, 261-281.

26. SAES Pure Gas I. Material Safety Data Sheet, MicroTorr Series, 602 Media; SAES Pure Gas: Billerica, USA, 2013.

27. Getters S. Customer Support; private communication, 2018.

28. SAES Pure Gas I. Material Safety Data Sheet, Micro Torr Series, 902 Media; SAES Pure Gas: Billerica USA, 2011.

29. Arbor S. Nahtlose Edelstahlrohre und Rohrbefestigungssysteme. Product-Catalog https://www.swagelok.de/downloads/ webcatalogs/de/MS-01-181.PDF (accessed Dec, 2019).

30. Ehlers A. W., Frenking G. Structures and bond energies of the transition-metal carbonyls $\mathrm{M}(\mathrm{CO})_{5}(\mathrm{M}=\mathrm{Fe}, \mathrm{Ru}, \mathrm{Os})$ and $\mathrm{M}(\mathrm{CO})_{4}$ ( $M=N \mathrm{Ni}, \mathrm{Pd}, \mathrm{Pt}$ ). Organometallics 1995, 14, 423-426.

31. Düllmann C. E., Eichler B., Eichler R., Gäggeler H. W., Jost D. T., Kindler U., Piguet D., Soverna S., Thörle P., Trautmann N., Türler A. Miss Piggy, a californium-252 fission fragment source as a generator of short-lived radionuclides. Nucl. Instrum. Methods Phys. Res. 2003, 512, 595-605.

32. Gorsich R. D. Preparation and properties of some mixed metal carbonyl compounds. I. Compounds containing a group IV metal and manganese or iron. J. Am. Chem. Soc. 1962, 84, 2486-2491.

33. Bhatt V. Essentials of Coordination Chemistry, Chapter 8 Metal Carbonyls, 1st ed.; Elsevier Inc., Academic Press: Amsterdam, 2015; pp. 191-236.

34. Baumgärtner F., Reichold P. Zur Chemie bei Kernprozessen. Z. Naturforsch. A. 1961, 16, 945-948.

35. Nucleonica. Database: ENDF/B-VIII.0, Karlsruhe, Germany https://www.nucleonica.com (accessed Aug, 2020).

36. Loveland W., Morrissey D. J., Seaborg G. T. Modern Nuclear Chemistry, Chapter 3 Radioactive Decay Kinetics; John Wiley \& Sons Inc: Hoboken, New Jersey, USA, 2017; pp. 57-90.

Supplementary Material: The online version of this article offers supplementary material (https://doi.org/10.1515/ract-2020-0036). 